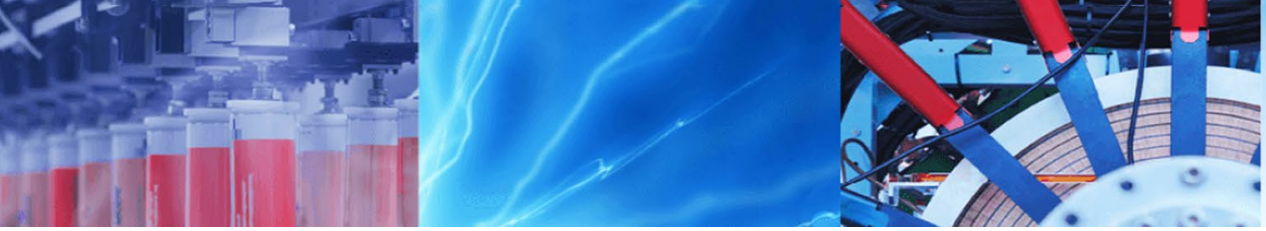

Research Article

\title{
Dielectric polarization and relaxation processes of the lithium-ion conducting PEO/PVDF blend matrix-based electrolytes: effect of $\mathrm{TiO}_{2}$ nanofiller
}

\author{
Priyanka Dhatarwal ${ }^{1}$ (D) R. J. Sengwa ${ }^{1}$ (i)
}

Received: 18 January 2020 / Accepted: 30 March 2020 / Published online: 7 April 2020

(c) Springer Nature Switzerland AG 2020

\begin{abstract}
The effect of $\mathrm{TiO}_{2}$ nanofiller concentration on the dielectric polarization and relaxation processes of (75PEO/25PVDF)/25 wt $\% \mathrm{LiClO}_{4}-x$ wt $\% \mathrm{TiO}_{2}(x=0,2,5,10,15$, and 20$)$ compositions based nanocomposite solid polymer electrolyte (NSPE) films has been investigated by employing the dielectric relaxation spectroscopy. The SEM micrographs demonstrate that the dispersion of $\mathrm{TiO}_{2}$ nanoparticles enormously alters the spherulitic morphology with the development of some cracks, pores, and wrinkles of these solution-cast prepared NSPE films. The X-ray diffraction study confirms that the heterostructures of these NSPE materials are semicrystalline and their degree of crystallinity increases irregularly with the increase of $\mathrm{TiO}_{2}$ concentration, however the crystallinity of host polymer blend matrix of these electrolytes decreases. The complex dielectric permittivity spectra of these NSPE materials in the frequency range from $20 \mathrm{~Hz}$ to $1 \mathrm{MHz}$ at $27^{\circ} \mathrm{C}$ reveal that there is a dominant contribution of electrode polarization and interfacial polarization at lower frequencies, whereas the high frequency permittivity values attribute to dipolar and ionic polarizations. Four types of relaxation processes have been probed by the 'master curve representation' of the dielectric and electrical spectra of these solid ion-dipole complexes. It is observed that the addition of $\mathrm{TiO}_{2}$ nanoparticles up to $10 \mathrm{wt} \%$ in these electrolytes influences the dielectric properties anomalously, but a huge decrease in the dielectric polarization and increase in the relaxation times are noted resulting in a significant decrease in the ionic conductivity of the film at $20 \mathrm{wt} \% \mathrm{TiO}_{2}$ concentration. The dependence of $d c$ ionic conductivity of these lithium-ion conducting NSPE materials on the chain segmental relaxation time and also the degree of crystallinity has been explored. The results of these NSPE materials have also been compared with the $\mathrm{TiO}_{2}$ nanoparticles loaded different polymer matrices and salts based electrolytes and discussed appropriately. These lithium-ion based electrolyte films are accredited for the solid-state ion-conducting energy storing devices from their electrochemical parameters characterized by LSV, CV, and CA techniques.
\end{abstract}

Keywords PEO/PVDF blend · Nanocomposite electrolytes · Dielectric relaxation · lonic conductivity · SEM · XRD

\section{Introduction}

The solid polymer electrolytes (SPEs) have attracted huge attention in the last four decades and now matured enough owing to their tremendous technological importance established in the development of flexible-type all-solid-state advanced ion-conducting devices (i.e., rechargeable batteries, fuel cells, supercapacitors, solar cells, sensors, and so forth) [1-10]. These materials are novel and advantageous over their liquid counterparts especially relevant to the battery applications because they have adequate ionic conductivity and numerous other fascinating features like wide operating temperature range, lightweight, good shelf life, high energy density,

Priyanka Dhatarwal, dhatarwalpriyanka@gmail.com; $₫$ R. J. Sengwa, rjsengwa@rediffmail.com; rjs.ph@jnvu.edu.in| ${ }^{1}$ Dielectric Research Laboratory, Department of Physics, Jai Narain Vyas University, Jodhpur 342 005, India. 
leakage-free, ease of preparation, the flexibility of miniaturization, reduced flammability, low toxicity, good stability during the charge-discharge cycles, as well as appreciable mechanical and thermal stabilities $[2,4,8-10]$. So far, a variety of SPEs including nanocomposite SPEs (NSPEs), plasticized SPEs (PSPEs), and plasticized nanocomposite SPEs (PNSPEs) have been beautifully developed with stateof-the-art, and their technological significance has been greatly appreciated with breakthroughs in the energy storing devices (batteries and supercapacitors) $[2,3,6-8,10$, 11]. At the early stage of the development of solid-state electrolyte materials, they exhibited some drawbacks from the technology point of view and therefore tremendous efforts have been made in the last decade researches to overcome the drawbacks and are thoroughly addressed in several recent reviews [1-12].

Many approaches such as the use of polymer blends as promising host matrices [13-19], inclusion of inorganic and organic nanofillers for improving thermal, mechanical, and ion transportation properties [20-23], the addition of various ionic liquid and/or dipolar liquid plasticizers for increasing degree of salt dissociation and reducing the crystallinity of polymer matrix [24-27], and consideration of different preparation methods suitable from the industrial point of view [28-33]. Furthermore, some combinations of these different approaches have also been taken into consideration for exploiting different kinds of SPE materials with a variety of appealing properties $[17,20$, $26,34]$. Among these approaches, the blending of polymers and their use as host matrices for the preparation of appropriate properties SPEs is a valid and more feasible green chemistry process that has been exemplified by various research groups [10, 17-21, 26, 29, 32]. The blending process not only suppresses the unwanted properties of individual polymers but also enhances the required superior properties that can be engineered through an appropriate compositional weight ratio of the blended polymers $[14,17,18,35,36]$. The addition of nano-sized fillers in the host polymer matrix is also a widely popular and efficient strategy to get improved physicochemical properties of the prepared NSPE materials $[6,10,18,22,30,37]$. It has been observed that the nanofiller increases free volume in the polymeric composite material and creates additional favourable ion conductive paths due to which ions mobility increases $[5,10]$. Further, numerous studies have also validated the fact that the nanofillers decrease the crystalline content of the semicrystalline polymer matrix and thereby make it more fascinating ion-conductive amorphous host medium $[22,23,37]$.

For the preparation of SPE films, the poly (ethylene oxide) (PEO) is extensively used as a host polymer matrix since the development of first-ever SPE material $[5,8,10]$, and it is still the prime choice of researchers for progressive work on the ion-conducting flexible-type SPE materials [38-41]. The key favorable properties of the PEO in regards to its use as SPE materials are its easy processing and high solvating power for the alkali metal salts $[5,8$, 10]. Although the degree of crystallinity of the PEO matrix $(\sim 73.6 \%)$ is high [42], its relatively fast chain segmental motion facilitates the hopping mechanism of ions transportation [33]. However, poor thermal and mechanical properties of the PEO matrix-based SPEs are major drawbacks in regard to device workability at higher temperatures $[5,10]$. Therefore, the blends of PEO with several polymers of better thermophysical properties are largely considered for the preparation of promising SPE, NSPE, PSPE, and PNSPE materials [14, 17-21, 26, 31, 32, 36, 43]. The semicrystalline polar poly(vinylidene fluoride) (PVDF) matrix has relatively appreciable physicochemical and electroactive properties [44] and therefore it is considered in several researches for the development of advanced SPE materials [45-47]. Numerous studies on the blend matrices of PEO/PVDF have realized some favourable properties in regards to their suitability as a host matrix for the SPEs and therefore this polymer blend matrix is used for the preparation of a variety of SPEs $[13-15,35,36,48]$ and also electrolyte membranes $[16,49,50]$ suitable for all-solidstate ion-conducting devices. A survey of literature confirms that for the lithium-ion conducting SPE materials, the $\mathrm{LiClO}_{4}$ is one of the appealing ionic dopants used enormously for the preparation of SPEs $[10,23,27,33,36]$. The investigations on numerous NSPE materials have claimed that the dispersion of $\mathrm{TiO}_{2}$ nanoparticles mostly increases the ionic conductivity, and some studies also reported an unexpected increase by a few orders of magnitude [22, $23,30,49-62]$. Some studies have concluded that only the acidic groups surface-modified $\mathrm{TiO}_{2}$ and some other inorganic nanofillers are effective in increasing the conductivity of the NSPE materials $[63,64]$. The molecular simulation studies established that the nanoparticles slow down the dynamics of polymer chain segments near their surface due to which mobility of ions reduces and thereby the ionic conductivity of the polymer electrolytes decreases in presence of a nanofiller $[65,66]$. Additionally, the study of $\mathrm{TiO}_{2}$ based NSPEs is not only interesting for the development of energy storage devices point of view but also highly appreciable in regards to energy harvesting devices $[49,67]$.

Recently, we investigated detailed structural and dielectric properties of the PEO/PVDF blends over the entire blend composition range [42], these polymers blends based nanocomposites [68], and also a variety of SPE materials $[35,69,70]$. In continuation of these researches on the PEO/PVDF blend matrix-based various types of flexible dielectric and electrolyte materials, the present manuscript deals with the NSPE materials comprising 
(75PEO/25PVDF)/25 wt $\% \mathrm{LiClO}_{4}-x$ wt $\% \mathrm{TiO}_{2}$ compositions. The manifold aims of this work are; first, to study and report the detailed morphological, structural, dielectric polarization and relaxations, and also ion conduction behaviour of these NSPE materials with the variation of $\mathrm{TiO}_{2}$ nanofiller concentration, second, to explore the effect of $\mathrm{TiO}_{2}$ concentration on the various relaxation times and their correlation with the ion transport mechanism in these heterogeneous ion-dipole complexes, and third, to confirm how much this wide bandgap semiconductor inorganic $\mathrm{TiO}_{2}$ nanofiller is effective in the improvement of the promising properties of PEO/PVDF blend matrix-based electrolyte materials.

\section{Experimental}

\subsection{Materials}

The Sigma-Aldrich PEO of $M_{\mathrm{v}}=600,000 \mathrm{~g} \mathrm{~mol}^{-1}$ (CAS No. 25322-68-3), PVDF of $M_{\mathrm{w}} \sim 534,000 \mathrm{~g} \mathrm{~mol}^{-1}$ (CAS No. 2493779-9), $\mathrm{LiClO}_{4}$ of battery grade (CAS No. 7791-03-9), and $\mathrm{TiO}_{2}$ of particle sizes less than $21 \mathrm{~nm}$ (CAS No. 13463-67-7) were used as primary materials for the preparation of the NSPE films. $\mathrm{N}, \mathrm{N}$-dimethyl formamide (DMF) (CAS No. 68-12-2) of Loba Chemie, India was used as the solvent.

\subsection{Preparation of NSPE films}

The NSPE films (i.e., (75PEO/25PVDF)/ $25 \mathrm{wt} \% \mathrm{LiClO}_{4}-x \mathrm{wt} \%$ $\left.\mathrm{TiO}_{2}\right)$ of varying $\mathrm{TiO}_{2}$ concentrations $(x=0,2,5,10,15$, and 20 wt $\%$ designated respectively as NSPE0 (i.e., SPE), NSPE2, NSPE5, NSPE10, NSPE15, and NSPE20) were obtained by casting from solution. Firstly, six polymeric solutions for PEO/PVDF blend of compositional weight ratio $75 / 25 \mathrm{wt} /$ $\mathrm{wt} \%$ were prepared by taking the amounts of PEO $(0.75 \mathrm{~g})$ and PVDF $(0.25 \mathrm{~g})$ in stoppered conical glass flasks for each sample, and dissolving them in DMF $(15 \mathrm{ml})$ at $80^{\circ} \mathrm{C}$ with magnetic stirring. Thereafter, $25 \mathrm{wt} \%$ amount of $\mathrm{LiClO}_{4}$ $(0.25 \mathrm{~g})$ with respect to the amount of polymer blend $(1 \mathrm{~g})$ was added to each polymeric solution and then these were again subjected to magnetic stirring for dissolution of the salt completely which resulted primary polymeric electrolyte solutions ((75PEO/25PVDF)/25 wt $\left.\% \mathrm{LiClO}_{4}\right)$. Thereafter, the required amounts of $\mathrm{TiO}_{2}$ for its $2(0.02 \mathrm{~g}), 5(0.05 \mathrm{~g})$, $10(0.10 \mathrm{~g}), 15(0.15 \mathrm{~g})$, and $20(0.20 \mathrm{~g}) \mathrm{wt} \%$ concentrations with respect to the amount of polymer blend $(1 \mathrm{~g})$ were dispersed in DMF and then added in respective five samples of the primary polymeric electrolyte solutions. These solutions were again stirred magnetically for $2 \mathrm{~h}$ to achieve good dispersibility of $\mathrm{TiO}_{2}$ nanoparticles in the electrolyte solutions. Finally, these five heterogeneous polymeric electrolyte solutions of different $\mathrm{TiO}_{2}$ concentrations and one sample of primary polymeric electrolyte solution were casted on to glass petri dishes. For the film formation, the casted solutions were heated at $70^{\circ} \mathrm{C}$ on a thermostated hot plate until the solvent evaporation was completed. These were then cooled down to room temperature which resulted free-standing NSPE films. All these films were vacuum dried at $40^{\circ} \mathrm{C}$ for a day to remove solvent traces and then were stored in the desiccator.

\subsection{Measurements}

The micro-images of NSPE0, NSPE5, and NSPE10 films and their EDX spectra were recorded by employing a scanning electron microscope (SEM; Carl ZEISS EVO MA15) equipped with energy dispersive $X$-ray (EDX) analyzer which run at EHT voltage of $15 \mathrm{kV}$. The XRD patterns of all these NSPE films were collected in reflection mode using the PANalytical X'pert Pro multipurpose powder diffractometer operated at $45 \mathrm{kV}$ and $40 \mathrm{~mA}$. The frequency dependent electrical measurements of each NSPE film sandwiched between the electrodes of dielectric test fixture were performed using Agilent Technologies 4284A precision LCR meter and 16451B solid dielectric test fixture. These measurements were carried out at 1-V electric signal of frequency range $20 \mathrm{~Hz}-1 \mathrm{MHz}$, at $27^{\circ} \mathrm{C}$. The measured values of frequency dependent electrical quantities (i.e., capacitance $C_{p}$, resistance $R_{\mathrm{p}}$ and dissipation factor $\left.\mathrm{D}(\tan \delta)\right)$ were used for the determination of complex dielectric permittivity, electrical conductivity, impedance, and electric modulus spectra of the NSPE films from the respective relations described elsewhere [70]. The electrochemical analyzer ( $\mathrm{CH}$ Instruments, Inc. CHI 608E) was employed for carrying out the linear sweep voltammetry (LSV), cyclic voltammetry (CV), and chronoamperometry (CA) of the NSPE films. A symmetrical cell for each film sandwiched between the stainless steel (SS) blocking electrodes was constructed for collecting LSV, CV, and CA traces following the procedure explained in the previous publication [71].

\section{Results and discussion}

\subsection{SEM images and microstructures}

Figure 1 presents the digital pictures, SEM images, and EDX spectra of NSPE0, NSPE5, and NSPE10 films as representative samples. It can be noted from the digital pictures that the NSPE0 film has some transparency but the $\mathrm{TiO}_{2}$ dispersed films are opaque and milky. The manual bending, twisting, and touching operations realize that the NSPEO film is little sticky and relatively more flexible whereas the stickiness and flexibility of the NSPE films reduce with the increase of $\mathrm{TiO}_{2}$ concentration. These manual observations 

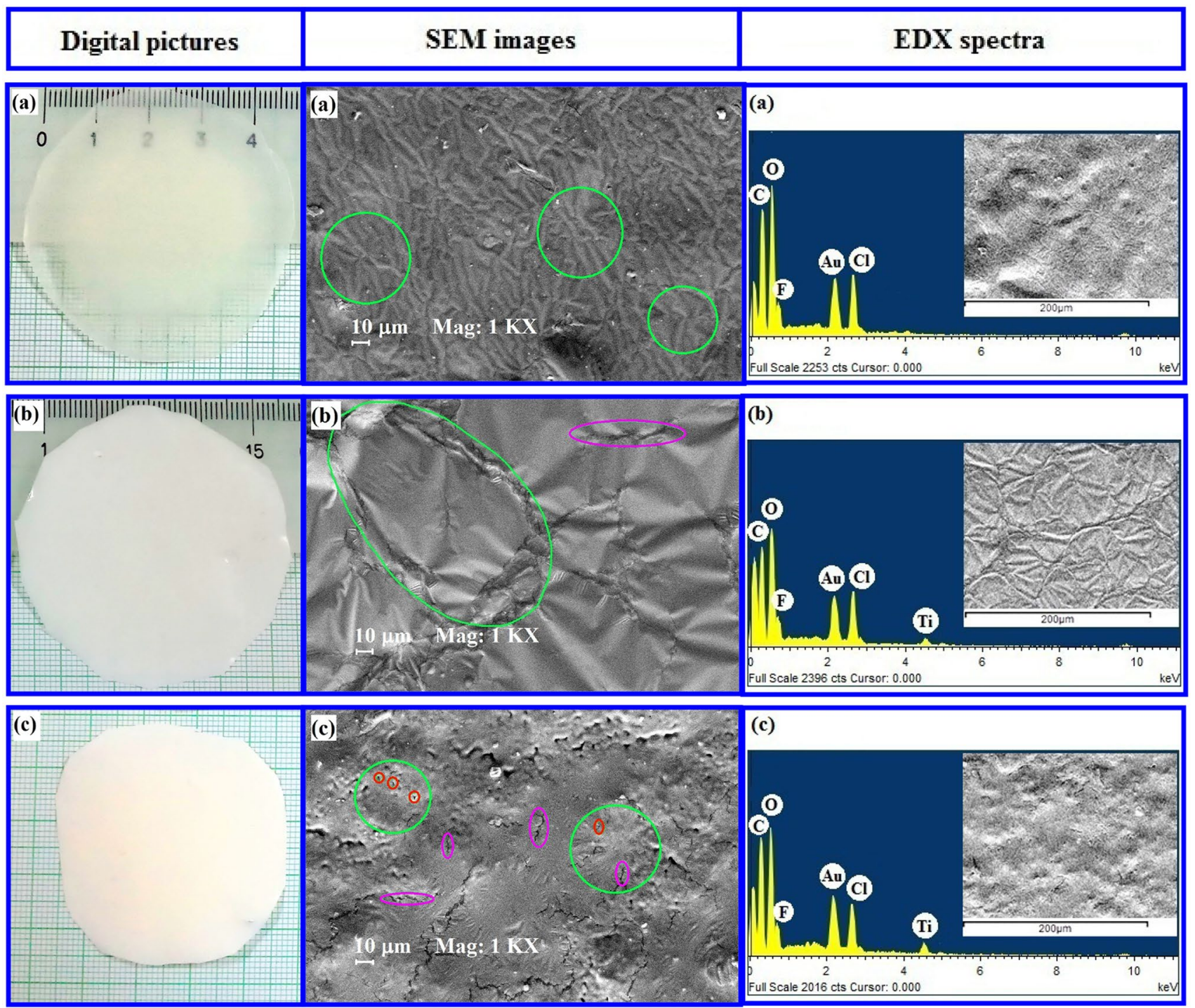

Fig. 1 The digital pictures, SEM images, and EDX spectra of (75PEO/25PVDF)/25 wt $\% \mathrm{LiClO}_{4}-x$ wt $\% \mathrm{TiO}_{2}$ films; a NSPE0 $(x=0)$ with encircled spherulites, b NSPE5 $(x=5)$ with typical cracked

infer that the $\mathrm{TiO}_{2}$ loading increases the mechanical strength of the NSPE films which are in agreement with earlier experimental results on the $\mathrm{TiO}_{2}$ containing other NSPE films [57, 58, 62].

The micrograph of NSPE0 film (Fig. 1a) shows that there are macro-sized spherulites (some are encircled) which represent the crystallites of PEO blended with PVDF [42], although, the pristine PEO and PVDF films exhibit highly distinguishable spherulites surrounded by the amorphous amount of these polymers [14, 42, 72]. The interconnected spherulites of the NSPEO film evidence cross-linked chain structures of the blended polymers through ion-dipole complexes due to which a large amount of these polymers crystals turn into amorphous content. Further, the earth texture encircled by ellipses, and c NSPE10 $(x=10)$ with encircled speherulits, and cracks and pores encircled by ellipses of different colors

wrinkles or fibril-like textures exhibited over the entire surface evidence large inner forces acting in these heteromaterials during the process of film formation as reported for a similar type of electrolyte materials [17]. Figure 1b reveals that 5 wt\% amount of $\mathrm{TiO}_{2}$ dispersed NSPE5 film exhibits highly different microstructures as compared to that of the NSPE0 film. Typical dry cracked earth texture with fluffier and crumpled structures can be seen in the micrograph of NSPE5 film. Further, when the $\mathrm{TiO}_{2}$ amount is increased up to $10 \mathrm{wt} \%$, then the NSPE10 film texture (Fig. 1c) turned rougher having several cracks with typical micro-sized pores. Some macro-size spherulitic features of typical granular shapes have also appeared which indicate strong electrostatic interaction of $\mathrm{TiO}_{2}$ nanoparticles with

\section{SN Applied Sciences}


the polymer structures. This SEM image also infers that the $\mathrm{TiO}_{2}$ nanoparticles exist almost homogeneously dispersed in the prepared film.

The EDX spectrum of NSPEO film (Fig. 1a) confirms that there is the presence of only its constituent elements which is evidence of the purity of film. This film has energy peaks of carbon (C) (at $0.28 \mathrm{keV})$, oxygen (O) (at $0.53 \mathrm{keV})$, fluorine (F) (at $0.68 \mathrm{keV})$, and chlorine (Cl) (at $2.62 \mathrm{keV}$ ) which are according to its composition. In addition to these peaks, the EDX spectra of NSPE5 (Fig. 1b) and NSPE10 (Fig. 1c) films also exhibit the peak of titanium (Ti) (at $4.51 \mathrm{keV}$ ) and its intensity is found high for the NSPE10 film as compared to that of the NSPE5 film, which is expected according to the increase in the concentration of $\mathrm{TiO}_{2}$ nanofiller. Further, the gold ( $\mathrm{Au}$ ) peak observed at $2.15 \mathrm{keV}$ in the EDX spectra of all these films is due to the use of this element for sputtering over the surfaces of the films prior to their EDX mapping.

\subsection{XRD spectra and crystal structures}

The XRD patterns in $2 \theta$ range from $10^{\circ}$ to $50^{\circ}$ of the (75PEO/25PVDF)/25 wt $\% \mathrm{LiClO}_{4}-x$ wt $\% \mathrm{TiO}_{2}$ films are depicted in Fig. 2. These patterns have moderate intensities peaks of the PEO, PVDF, and $\mathrm{TiO}_{2}$ representing their crystalline content (marked in the figure), and also a huge background hump in each pattern attributing to amorphous content. These patterns confirm that these semicrystalline films are predominantly amorphous. The assignments of main crystalline peaks with their positions $2 \theta$, reflection plane indices $(h k l)$, and the determined values of basal spacing $d$, full width at half maximum (FWHM) $\beta$, crystallite size $L$, and intensity / for all these NSPE films are listed in Table 1.

The NSPEO (primary SPE without nanofiller) film displays the characteristic peaks of PEO $\left(19.11^{\circ}\right.$ and $\left.23.38^{\circ}\right)$ but their intensities are much lower than that of the pristine PEO film [33] revealing that a large amount of PEO crystallites have turned into amorphous content due to formation of ion-dipole complexes. A significant intensity $\beta$-phase $\left(20.53^{\circ}\right)$, a very low intensity $\gamma$-phase $\left(22.02^{\circ}\right)$, and also a-phase $\left(36.32^{\circ}\right)$ crystals peaks in the XRD pattern of this film confirms the PVDF polymorphism [15, 42, 44, 62]. Further, as compared to peaks intensities and positions of NSPEO film, it is found that there is an increase in intensities of the PEO and PVDF peaks with a small change in their positions for the NSPE2 film (see $2 \theta$ and / values given in Table 1). Furthermore, a low intensity peak at $25.17^{\circ}(101)$ is also exhibited in the XRD pattern of this film which is the main characteristic peak of tetragonal anatase $\mathrm{TiO}_{2}$ [73]. Besides this peak, several weak intensity peaks around $27^{\circ}, 36.08^{\circ}, 37.75^{\circ}$, and $47.92^{\circ}$ can be noted with increasing $\mathrm{TiO}_{2}$ contents in the films attributing to

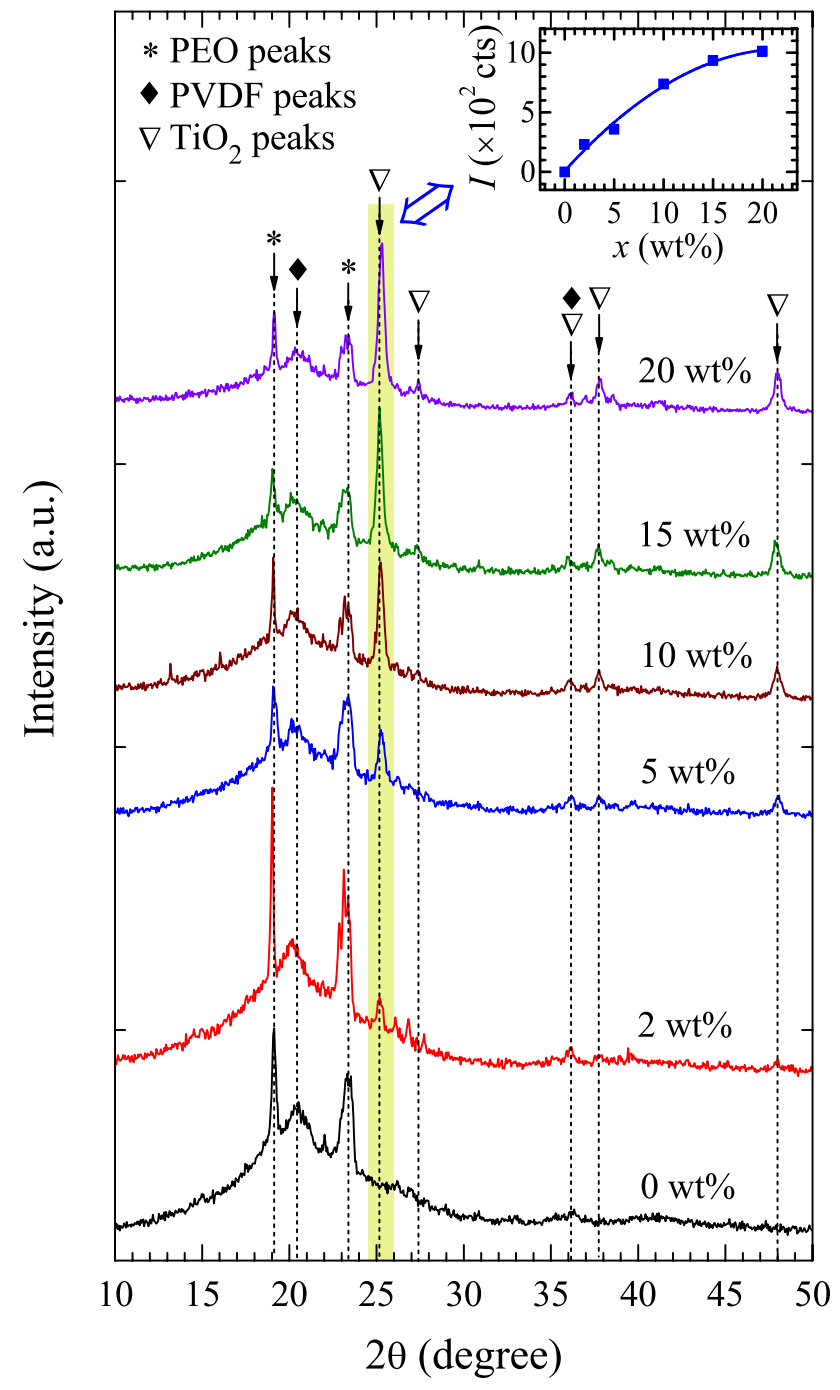

Fig. 2 The XRD patterns of (75PEO/25PVDF)/25 wt $\% \mathrm{LiClO}_{4}-x$ wt $\%$ $\mathrm{TiO}_{2}$ films $(x=0,2,5,10,15$, and 20) marked with PEO, PVDF, and $\mathrm{TiO}_{2}$ peaks and the characteristic $\mathrm{TiO}_{2}$ peak highlighted with a coloured background. The plot of intensity I versus $x$ (wt\%) for the characteristic intense peak of $\mathrm{TiO}_{2}$ at $\sim 25^{\circ}$ (101) of these NSPE films is shown in the inset

anatase and rutile phases of $\mathrm{TiO}_{2}$ [73]. It is also observed from these XRD patterns that with the increase of $\mathrm{TiO}_{2}$ concentrations up to $20 \mathrm{wt} \%$, the peaks intensities of both the polymers decrease anomalously, whereas there is a gradual increase in the intensities of $\mathrm{TiO}_{2}$ peaks. The main characteristic peak of $\mathrm{TiO}_{2}$ is highlighted with a coloured background in Fig. 2 for these NSPE films. The inset of this figure shows the plot of $\mathrm{TiO}_{2}$ peak intensity versus $x$ (wt\%) which increases non-linearly with the increase of $\mathrm{TiO}_{2}$ content in these NSPE films. This finding evidence that the nanoparticles incorporated in these electrolyte films are uniformly distributed over the entire volume of each NSPE film. Further, the major crystallite peaks of pristine 
Table 1 Values of $2 \theta, d, \beta$, $L$, and / corresponding to various diffraction peaks of (75PEO/25PVDF)/25 wt\% $\mathrm{LiClO}_{4}-x \mathrm{wt} \% \mathrm{TiO}_{2}$ films

\begin{tabular}{|c|c|c|c|c|c|}
\hline Diffraction peaks & $2 \theta$ (degree) & $d(\mathrm{~nm})$ & $\beta\left(\times 10^{-3} \mathrm{rad}\right)$ & $L(\mathrm{~nm})$ & $I$ (counts) \\
\hline \multicolumn{6}{|c|}{ (75PEO/25PVDF)/25 wt\% $\mathrm{LiClO}_{4}$ film (NSPE0) } \\
\hline PEO (120) & 19.11 & 0.464 & 4.59 & 31.99 & 778 \\
\hline$\beta$ PVDF (110),(200) & 20.53 & 0.432 & 17.65 & 8.34 & 263 \\
\hline ү PVDF (020) & 22.02 & 0.403 & 2.50 & 59.11 & 123 \\
\hline PEO (112),(032) & 23.38 & 0.380 & 13.11 & 11.28 & 640 \\
\hline a PVDF (200) & 36.32 & 0.247 & 10.90 & 13.97 & 65 \\
\hline \multicolumn{6}{|c|}{ (75PEO/25PVDF)/25 wt $\% \mathrm{LiClO}_{4}-2$ wt $\% \mathrm{TiO}_{2}$ film (NSPE2) } \\
\hline PEO (120) & 19.02 & 0.466 & 2.89 & 49.20 & 1208 \\
\hline$\beta$ PVDF (110),(200) & 20.14 & 0.440 & 16.63 & 8.84 & 282 \\
\hline PEO (112),(032) & 23.14 & 0.384 & 12.28 & 12.03 & 890 \\
\hline $\mathrm{TiO}_{2}(101)$ & 25.17 & 0.353 & 6.99 & 21.20 & 230 \\
\hline \multicolumn{6}{|c|}{ (75PEO/25PVDF)/25 wt $\% \mathrm{LiClO}_{4}-5 \mathrm{wt} \% \mathrm{TiO}_{2}$ film (NSPE5) } \\
\hline PEO (120) & 19.09 & 0.465 & 5.67 & 25.89 & 470 \\
\hline$\beta$ PVDF (110),(200) & 20.17 & 0.440 & 17.08 & 8.61 & 193 \\
\hline PEO (112),(032) & 23.32 & 0.381 & 13.98 & 10.58 & 508 \\
\hline $\mathrm{TiO}_{2}(101)$ & 25.26 & 0.352 & 7.33 & 20.25 & 358 \\
\hline \multicolumn{6}{|c|}{ (75PEO/25PVDF)/25 wt\% $\mathrm{LiClO}_{4}-10$ wt $\% \mathrm{TiO}_{2}$ film (NSPE10) } \\
\hline PEO (120) & 19.07 & 0.465 & 3.07 & 47.80 & 498 \\
\hline$\beta$ PVDF (110),(200) & 20.46 & 0.434 & 16.93 & 8.69 & 200 \\
\hline PEO (112),(032) & 23.18 & 0.383 & 9.29 & 15.92 & 376 \\
\hline $\mathrm{TiO}_{2}(101)$ & 25.24 & 0.353 & 6.98 & 21.26 & 738 \\
\hline \multicolumn{6}{|c|}{ (75PEO/25PVDF)/25 wt\% $\mathrm{LiClO}_{4}-15$ wt $\% \mathrm{TiO}_{2}$ film (NSPE15) } \\
\hline PEO (120) & 19.03 & 0.466 & 5.39 & 27.23 & 375 \\
\hline$\beta$ PVDF (110),(200) & 20.12 & 0.441 & 20.75 & 7.09 & 184 \\
\hline PEO (112),(032) & 23.24 & 0.382 & 13.44 & 11.00 & 356 \\
\hline $\mathrm{TiO}_{2}(101)$ & 25.19 & 0.353 & 7.14 & 20.79 & 935 \\
\hline \multicolumn{6}{|c|}{ (75PEO/25PVDF)/25 wt\% $\mathrm{LiClO}_{4}-20$ wt $\% \mathrm{TiO}_{2}$ film (NSPE20) } \\
\hline PEO (120) & 19.13 & 0.464 & 3.12 & 47.00 & 418 \\
\hline$\beta$ PVDF (110),(200) & 20.35 & 0.436 & 22.75 & 6.46 & 143 \\
\hline PEO (112),(032) & 23.46 & 0.379 & 12.93 & 11.44 & 291 \\
\hline $\mathrm{TiO}_{2}(101)$ & 25.29 & 0.352 & 7.10 & 20.89 & 1013 \\
\hline
\end{tabular}

$\mathrm{LiClO}_{4}\left(21.02^{\circ}\right.$ and $\left.23.04^{\circ}\right)$ [74] are not exhibited in these XRD patterns which confirms the complete dissolution of the added amount of salt in the prepared NSPE materials.

The degree of crystallinity $X_{c}$ of the electrolyte films (i.e., $X_{c(p)}$ of the host polymer matrix and $X_{c(t)}$ of the total bulk composite material) were determined from the areas of crystalline and amorphous parts in XRD patterns using the area-based relation given in the literature $[42,68]$. It can be noted from Table 2 that the $X_{c(p)}$ values of $\mathrm{TiO}_{2}$ dispersed NSPE films are significantly lower whereas $X_{c(\mathrm{t})}$ values are
Table 2 Values of degree of crystallinity $X_{c(p)}(\%)$ and $X_{c(t)}$ (\%), various relaxation times $\tau_{E D L}, \tau_{M W S}, \tau_{s^{\prime}}$ and $\tau_{\sigma}$ dc ionic conductivity $\sigma_{\mathrm{dc}}$ $\left(\sigma_{\mathrm{dc}\left(\sigma^{\prime}\right)}\right.$ and $\left.\sigma_{\mathrm{dc}(\mathrm{Rb})}\right)$, fractional exponent $n$, and total ion transference number $t_{\text {ion }}$ of (75PEO/25PVDF)/25 wt $\% \mathrm{LiClO}_{4}-x$ wt $\% \mathrm{TiO}_{2}$ films for $x=0,2,5,10,15$, and 20

\begin{tabular}{|c|c|c|c|c|c|c|c|c|c|c|}
\hline NSPE films & $X_{c(p)}(\%)$ & $X_{\mathrm{c}(\mathrm{t})}(\%)$ & $\tau_{\mathrm{EDL}}\left(\times 10^{-4} \mathrm{~s}\right)$ & $\tau_{\text {MWS }}\left(\times 10^{-5} \mathrm{~s}\right)$ & $\tau_{s}\left(\times 10^{-6} s\right)$ & $\tau_{\sigma}\left(\times 10^{-7} \mathrm{~s}\right)$ & $\sigma_{\mathrm{dc}\left(\sigma^{\prime}\right)}(\mu \mathrm{S} / \mathrm{cm})$ & $\sigma_{\mathrm{dc}(\mathrm{Rb})}(\mu \mathrm{S} / \mathrm{cm})$ & $n$ & $t_{\text {ion }}$ \\
\hline NSPEO & 22.9 & 22.9 & 5.31 & 2.10 & 1.69 & 1.34 & 3.25 & 5.3 & 0.50 & 0.990 \\
\hline NSPE2 & 17.5 & 24.2 & 10.62 & 3.46 & 3.09 & 3.08 & 2.40 & 3.8 & 0.73 & 0.938 \\
\hline NSPE5 & 15.4 & 24.7 & 8.80 & 2.45 & 1.96 & 1.71 & 2.60 & 4.5 & 0.57 & 0.970 \\
\hline NSPE10 & 17.3 & 26.4 & 13.05 & 2.97 & 1.89 & 1.54 & 2.95 & 4.6 & 0.72 & 0.941 \\
\hline NSPE15 & 16.8 & 34.9 & 3.55 & 1.72 & 1.74 & 2.08 & 2.42 & 4.0 & 0.62 & 0.976 \\
\hline NSPE20 & 13.0 & 37.0 & 5.94 & 3.31 & 5.89 & 12.92 & 0.47 & 0.8 & 0.68 & 0.931 \\
\hline
\end{tabular}


higher as compared to that of the NSPEO (SPE film without nanofiller). Further, these $X_{c}$ values anomalously vary with the increase of $\mathrm{TiO}_{2}$ concentration in the NSPE films. The effect of $X_{c(p)}$ and $X_{c(t)}$ values on the ionic conductivity of these NSPE films is considered in the later section of this manuscript.

\subsection{Dielectric spectra and polarization processes}

Figure 3 presents the complex dielectric permittivity (real part $\varepsilon^{\prime}$ and imaginary part $\left.\varepsilon^{\prime \prime}\right)$ and dielectric loss tangent $\left(\tan \delta=\varepsilon^{\prime \prime} / \varepsilon^{\prime}\right)$ values as a function of frequency for the (75PEO/25PVDF)/25wt $\% \mathrm{LiClO}_{4}-x \mathrm{wt} \% \mathrm{TiO}_{2}$ films, at 27

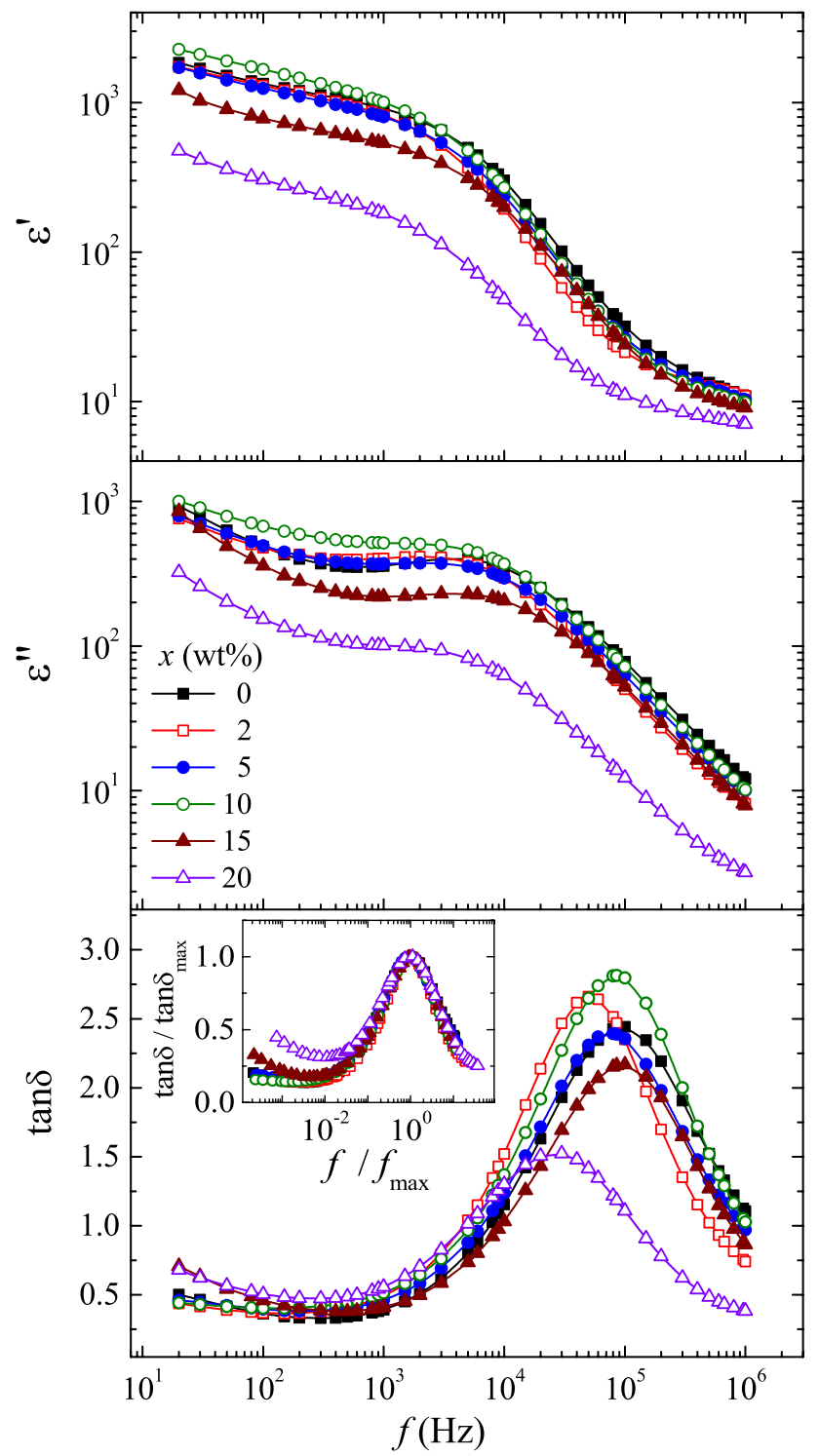

Fig. 3 The spectra of complex dielectric permittivity (real part $\varepsilon^{\prime}$ and imaginary part $\left.\varepsilon^{\prime \prime}\right)$ and dielectric loss tangent tan $\delta$ of (75PEO/25PVDF) $/ 25 \mathrm{wt} \% \mathrm{LiClO}_{4}-x \mathrm{wt} \% \mathrm{TiO}_{2}$ films $(x=0,2,5,10,15$, and 20$)$, at $27^{\circ} \mathrm{C}$. Inset shows the scaled plots of $\tan \delta$ spectra
${ }^{\circ} \mathrm{C}$. It can be noted that the respective shapes of these spectra of $\varepsilon^{\prime}, \varepsilon^{\prime \prime}$, and $\tan \delta$ for all the NSPE films are almost identical. Further, at a fixed frequency, there are relatively small changes in $\varepsilon^{\prime}$ and $\varepsilon^{\prime \prime}$ values with the increase of $\mathrm{TiO}_{2}$ concentration up to $10 \mathrm{wt} \%$, but a noticeable decrease at $15 \mathrm{wt} \%$ in the lower frequency range and a huge decrease at $20 \mathrm{wt} \%$ over the entire frequency range is observed. These results verify that there is a moderate alteration in the overall amount of ion-dipole ordering in the presence of $\mathrm{TiO}_{2}$ nanoparticles up to $10 \mathrm{wt} \%$ but a large disordering is exhibited for the higher concentration of the nanofiller. The magnitude and dispersion trend of frequency dependent $\varepsilon^{\prime}$ and $\varepsilon^{\prime \prime}$ values for these films evidence the existence of four types of dielectric polarization processes in the frequency range from $20 \mathrm{~Hz}-1 \mathrm{MHz}$ which are demonstrated for some other electrolyte materials in recent publications $[69,70]$. The dominance of the electrode polarization (EP) process is exhibited at lower frequencies as evident from the high dielectric permittivity values of about three orders of magnitude for these NSPE films. Further, at intermediate frequencies, there is a significant contribution of interfacial polarization (IP) process in these heterogeneous materials due to which there is a slow decrease in $\varepsilon^{\prime}$ values and $\varepsilon^{\prime \prime}$ values resulting a hump in the frequency range from $1 \mathrm{kHz}-10 \mathrm{kHz}$. A huge dispersion of $\varepsilon^{\prime}$ and $\varepsilon^{\prime \prime}$ values at higher frequencies can be attributed, firstly to the molecular polarization and then the ionic polarization with increasing frequency. The probing of relaxations corresponding to these processes is executed with the help of 'master curve representation' in the later section.

The $\tan \delta$ spectra of these NSPE materials characteristically exhibit the intense relaxation peaks in the high frequency region which are corresponding to the ions coupled chain segmental motion. It can be noted that the intensities and positions of the $\tan \delta$ peaks anomalously change with the increase of $\mathrm{TiO}_{2}$ concentration in these NSPE films which reveals that the heterogeneous ion-dipole-nanoparticle interactions vary irregularly and hence the dielectric properties of these materials cannot be tuned by changing $\mathrm{TiO}_{2}$ concentration. The scaled plots of $\tan \delta$ spectra (i.e. $\tan \delta / \tan \delta_{\max }$ versus $f / f_{\max }$ ) shown in the inset of the figure for these NSPE materials are found reasonably overlapped (except NSPE20 film at lower frequencies) which manifests that they have a similar trend of the distribution of their main relaxation time [69]. The deviation at lower frequencies evidences a significant difference in electrode polarization behaviour of these NSPE materials of nanofiller concentration $>10$ wt $\%$.

\subsection{Conductivity spectra and charge transportation}

Figure 4 demonstrates the ac electrical conductivity (real part $\sigma^{\prime}$ ) spectra of the NSPE films at $27^{\circ} \mathrm{C}$, which exhibit 


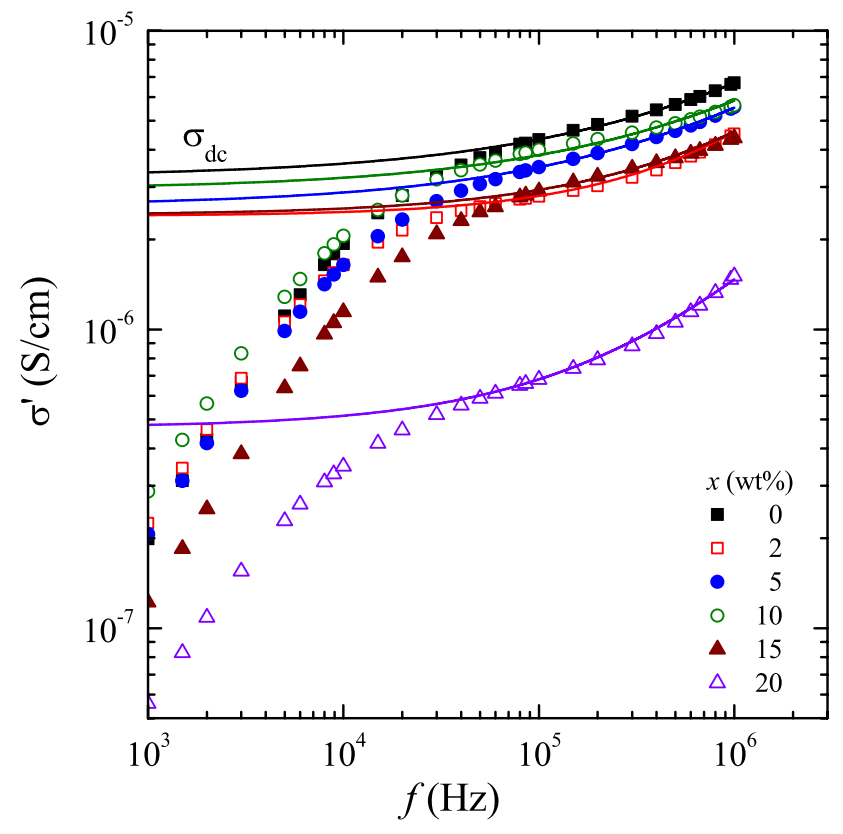

Fig. 4 The spectra of real part $\sigma^{\prime}$ of ac electrical conductivity for (75PEO/25PVDF)/25 wt $\% \mathrm{LiClO}_{4}-x$ wt $\% \mathrm{TiO}_{2}$ films $(x=0,2,5,10,15$, and 20$)$, at $27^{\circ} \mathrm{C}$. Solid lines on these $\sigma^{\prime}$ spectra are the power law fit $\sigma^{\prime}(\omega)=\sigma_{\mathrm{dc}}+A \omega^{n}$ of high frequency experimental data

all the characteristic dispersion regions similar to those demonstrated for other electrolyte materials investigated earlier $[19,20,31-34,43,53,69,70]$. In the low frequency region, the $\sigma^{\prime}$ values increase sharply with the increase of frequency owing to the fast suppression of the electric double layer (EDL) capacitances which are relatively large at the initial frequency of the spectra. After full suppression of the EDLs, these spectra firstly exhibit a very narrow range of dc plateau and then show dc to ac transition of the charge carriers according to Jonscher power law relation $\sigma^{\prime}(\omega)=\sigma_{\mathrm{dc}}+A \omega^{n}$. The power law fits of high frequency $\sigma^{\prime}$ data points are shown by solid lines on the spectra in the figure, and the observed values of fit parameters i.e., dc ionic conductivity $\sigma_{\mathrm{dc}}$ (denoted as $\sigma_{\mathrm{dc}\left(\sigma^{\prime}\right)}$ ) and fractional exponent $n$ of these NSPE films are listed in Table 2. The $\sigma_{\mathrm{dc}}$ values are found of the order of $10^{-6} \mathrm{~S} / \mathrm{cm}$ for these NSPE films which show a small variation with the increase of $\mathrm{TiO}_{2}$ concentration up to $15 \mathrm{wt} \%$. The $\sigma_{\mathrm{dc}}$ value of $20 \mathrm{wt} \% \mathrm{TiO}_{2}$ containing NSPE20 film is found about one order of magnitude lower in comparison to the other low concentration $\mathrm{TiO}_{2}$ containing NSPE films (see Table 2). Further, it can be noted that the $\sigma_{\mathrm{dc}}$ values of all the $\mathrm{TiO}_{2}$ containing NSPE films are lower than that of the NSPEO film without nanofiller. This finding confirms that the dispersion of $\mathrm{TiO}_{2}$ nanoparticles in the primary composition of these electrolytes is not effective in regards to enhancing the ion transport mechanism. Further, the $n$ values of these NSPE materials are found in the range 0.50 to 0.73 , which are much

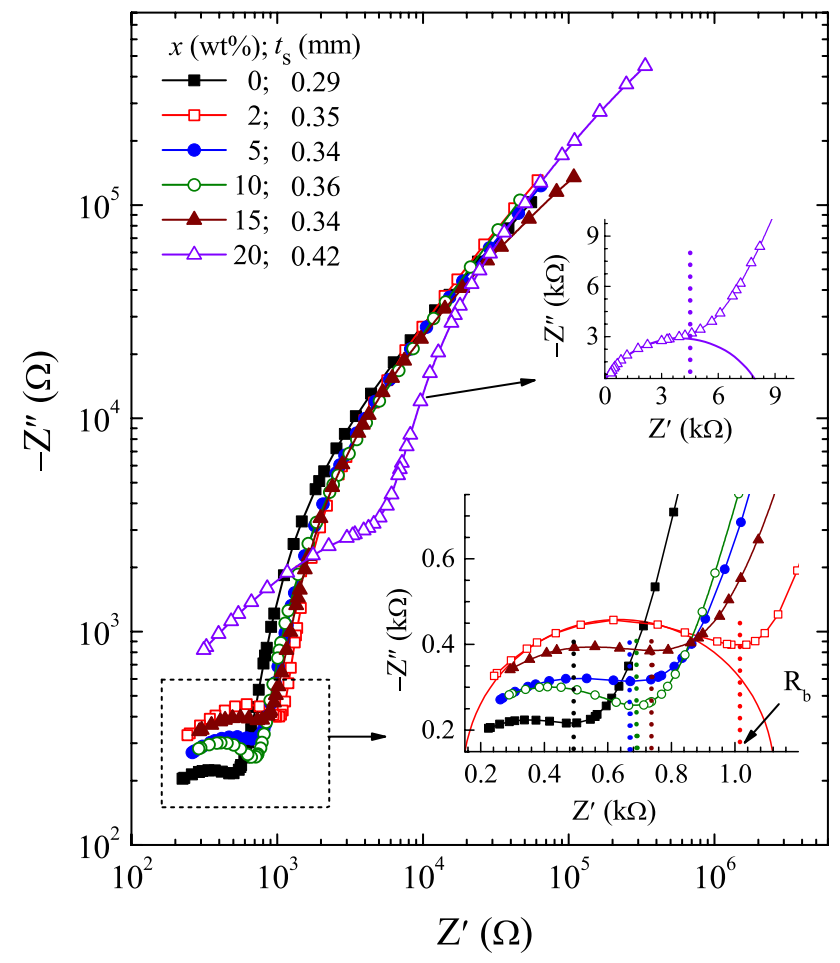

Fig. 5 Complex impedance plane plots $\left(Z^{\prime \prime}\right.$ versus $\left.Z^{\prime}\right)$ for (75PEO/25PVDF)/25 wt $\% \mathrm{LiClO}_{4}-x$ wt $\% \mathrm{TiO}_{2}$ films $(x=0,2,5,10,15$, and 20) of thicknesses $t_{\mathrm{s}}(\mathrm{mm})$, at $27^{\circ} \mathrm{C}$. Insets show the enlarged view of high frequencies on the linear scale and bulk resistances $R_{\mathrm{b}}$ marked with vertical dashed lines, and semicircle drawn with high frequency data for the NSPE2 $(x=2)$ and NSPE20 $(x=20)$ films

lower than unity confirming that the ion transportation takes place predominantly through hopping mechanism and this fact agrees with the results on several other SPE materials investigated with dielectric spectroscopy $[20,21$, $29,31-33,70]$.

\subsection{Complex impedance plots}

The Nyquist plots of frequency dependent complex impedance data ( $Z^{\prime \prime}$ versus $Z^{\prime}$ ) on the logarithmic scale for the NSPE films at $27^{\circ} \mathrm{C}$ are given in Fig. 5. All these complex plane plots exhibit two characteristic parts of the electrolyte films; (i) the tilted large spikes formed by low frequency data representing the EDL capacitances, and (ii) the small sized arcs formed by the high frequency data (enlarged view on the linear scale shown in insets of the figure which are parts of semicircle drawn for some representative samples) attributing to bulk properties of the electrolyte materials. Each arc represents the equivalent parallel combination circuit of an energy storing element $C_{\mathrm{p}}$ and a dissipating element $R_{\mathrm{p}}$. The shapes of these impedance plots are found in good resemblance with that of the several similar types of electrolyte 
materials based on different polymer matrices $[14,26$, $30,32,35,43,69]$. Further, the shape of the Nyquist plot of NSPE20 film indicates that the arc and spike parts in the plot are not clearly separable as usually noted for the other electrolytes which reflect that there may be few stiffer domains on the film surfaces resulting in poor electrode/electrolyte contact [70].

The bulk resistance $R_{\mathrm{b}}$ which is the dc resistance of the electrolyte material was noted from the real axis $Z^{\prime}$ for each film at which the arc and spike intersect as marked by vertical dashed lines in the figure. Taking these $R_{\mathrm{b}}$ values and the film thicknesses $t_{\mathrm{s}}$ marked in Fig. 5 , the $\mathrm{dc}$ ionic conductivities were determined by the relation $\sigma_{\mathrm{dc}}=t_{\mathrm{s}} / R_{\mathrm{b}}$. $A$ where $A=11.35 \mathrm{~cm}^{2}$ is the active electrode surface area of the test fixture. The observed $\sigma_{\mathrm{dc}}$ (denoted by $\sigma_{\mathrm{dc}(\mathrm{Rb})}$ ) values for these films from this $R_{\mathrm{b}}$ based relation are also listed in Table 2. It can be noted from this table that the $\sigma_{\mathrm{dc}(\mathrm{Rb})}$ and $\sigma_{\mathrm{dc}\left(\sigma^{\prime}\right)}$ values for each sample are of the same order of magnitude which validates the suitability of both the methods used for determination of ionic conductivity of the solid polymer electrolytes. Some differences may be there in the $\sigma_{\mathrm{dc}\left(\sigma^{\prime}\right)}$ and $\sigma_{\mathrm{dc}(\mathrm{Rb})}$ values of the ion-conducting electrolytes because of possible error in the estimated $R_{\mathrm{b}}$ values from the complex impedance plots as explained earlier [20,32, 39, 69-71].

\subsection{Electric modulus spectra}

The complex electric modulus (real part $M^{\prime}$ and imaginary part $M^{\prime \prime}$ ) spectra for the NSPE materials at $27^{\circ} \mathrm{C}$ are depicted in Fig. 6 . These spectra on semi-logarithmic scale reveal that the low frequency range in which the $M^{\prime}$ and $M^{\prime \prime}$ values are about zero represents the EP dominated region, whereas the steep rise in the high frequency range attributes to bulk properties of the electrolyte materials which are common characteristics reported for several electrolyte materials $[18-21,35,69$, 70]. The $M$ " spectrum of the NSPE20 film exhibits a peak at about $200 \mathrm{kHz}$ corresponding to the conductivity relaxation process at which the long range motion of charge carriers turn to localized hopping mechanism [26, $32,33,71,75]$. The shape of $M$ " spectra for the NSPE films containing $\mathrm{TiO}_{2}$ concentration $0 \leq x \leq 15$ reflects that conductivity relaxation process peaks of these materials are just above $1 \mathrm{MHz}$ confirming their relatively fast hopping mechanism as compared to that of the NSPE20 film. The Nyquist plot $\left(M^{\prime \prime}\right.$ versus $\left.M^{\prime}\right)$ of the NSPE5 film as a representative is shown in the inset of the figure which confirms the Cole-Cole dispersion of its conductivity relaxation process, and the same is true for the other NSPE materials.

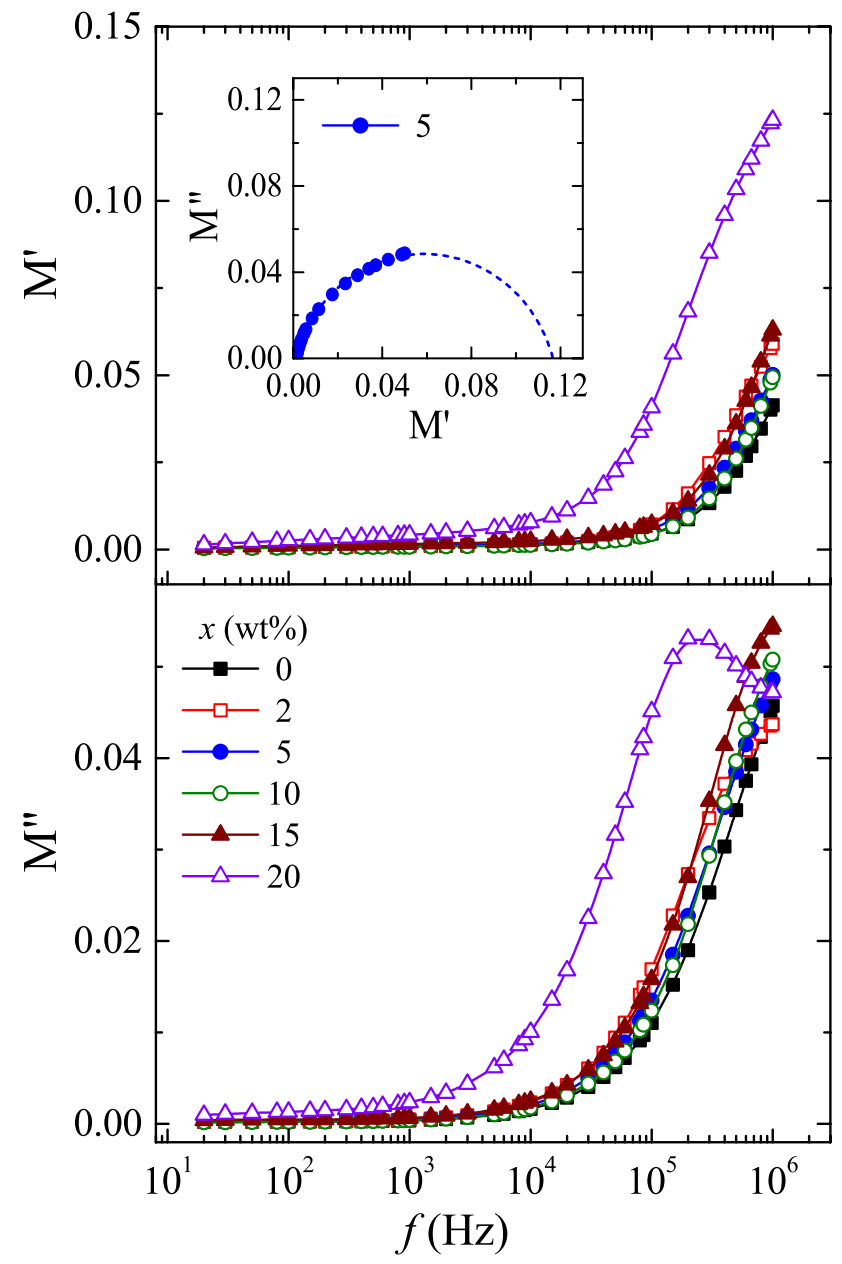

Fig. 6 The electric modulus spectra (real part $M^{\prime}$ and imaginary part $\left.M^{\prime \prime}\right)$ of (75PEO/25PVDF)/25 wt $\% \mathrm{LiClO}_{4}-x$ wt $\% \mathrm{TiO}_{2}$ films $(x=0$, $2,5,10,15$, and 20$)$, at $27^{\circ} \mathrm{C}$. Inset shows the Cole-Cole plot for the NSPE5 $(x=5)$ film

\subsection{Confirmation of relaxation processes}

Figure 7 shows a novel procedure of probing different relaxation processes in the heterogeneous electrolytes by 'master curve representation' of all the dielectric and electric functions which is explained in the recent publications $[69,70,75]$. This figure shows the spectra of dielectric and electric functions drawn on the same frequency scale for NSPE2 (Fig. 7a) and NSPE20 (Fig. 7b) films as representatives of these materials. The frequencies corresponding to four different relaxation processes occurring in the frequency range from $20 \mathrm{~Hz}$ to $1 \mathrm{MHz}$ are marked by vertical dashed lines in this figure. These relaxation processes denoted by the frequencies $f_{\mathrm{EDL}}, f_{\mathrm{MWs}}, f_{\mathrm{s}}$ and $f_{\sigma}$ in the figure are corresponding to the charging and discharging of EDL capacitances, charge dynamics of the MWS mechanism with a significant contribution of the EDLs relaxation, ions coupled chain segmental motion, and the ionic 


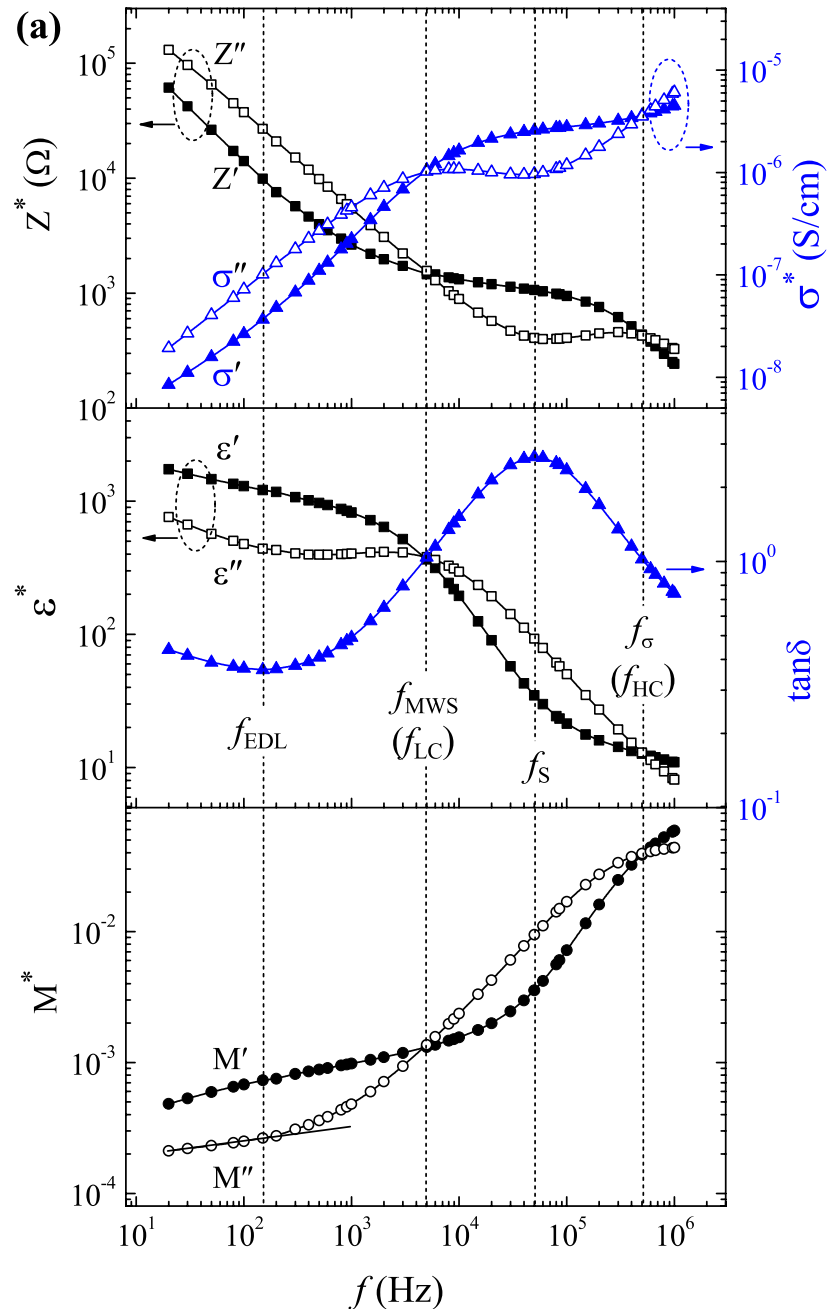

Fig. 7 'Mater curve representation' of various dielectric and electrical functions for (75PEO/25PVDF)/25wt $\% \mathrm{LiClO}_{4}-x$ wt $\% \mathrm{TiO}_{2}$ films; a NSPE2 $(x=2)$ and $\mathbf{b}$ NSPE20 $(x=20)$ at $27^{\circ} \mathrm{C}$. The relaxation fre-

conductivity relaxation, respectively. The detailed identification procedure of these relaxation processes for the complex SPE materials is demonstrated in our recent publications [70].

For these NSPE films, the lower cross-frequency $f_{\mathrm{LC}}$ and the higher cross-frequency $f_{\mathrm{HC}}$ of the real and imaginary parts of the dielectric and electric functions can be assigned to the MWS and conductivity relaxation processes, respectively. For non-Debye type ac electrical conductivity dispersion of the electrolyte materials, the conductivity relaxation frequency $f_{\sigma}$ appears at a little higher value than the $f_{\mathrm{HC}}$, but the trend of variation of $f_{\sigma}$ with the change in the composition of the electrolytes seems to remain same as that noted in the $f_{\mathrm{HC}}$ values. Further, the frequency corresponding to the minimum of $\tan \delta$ and $\varepsilon^{\prime \prime}$ in the lower frequency region where $M^{\prime \prime}$

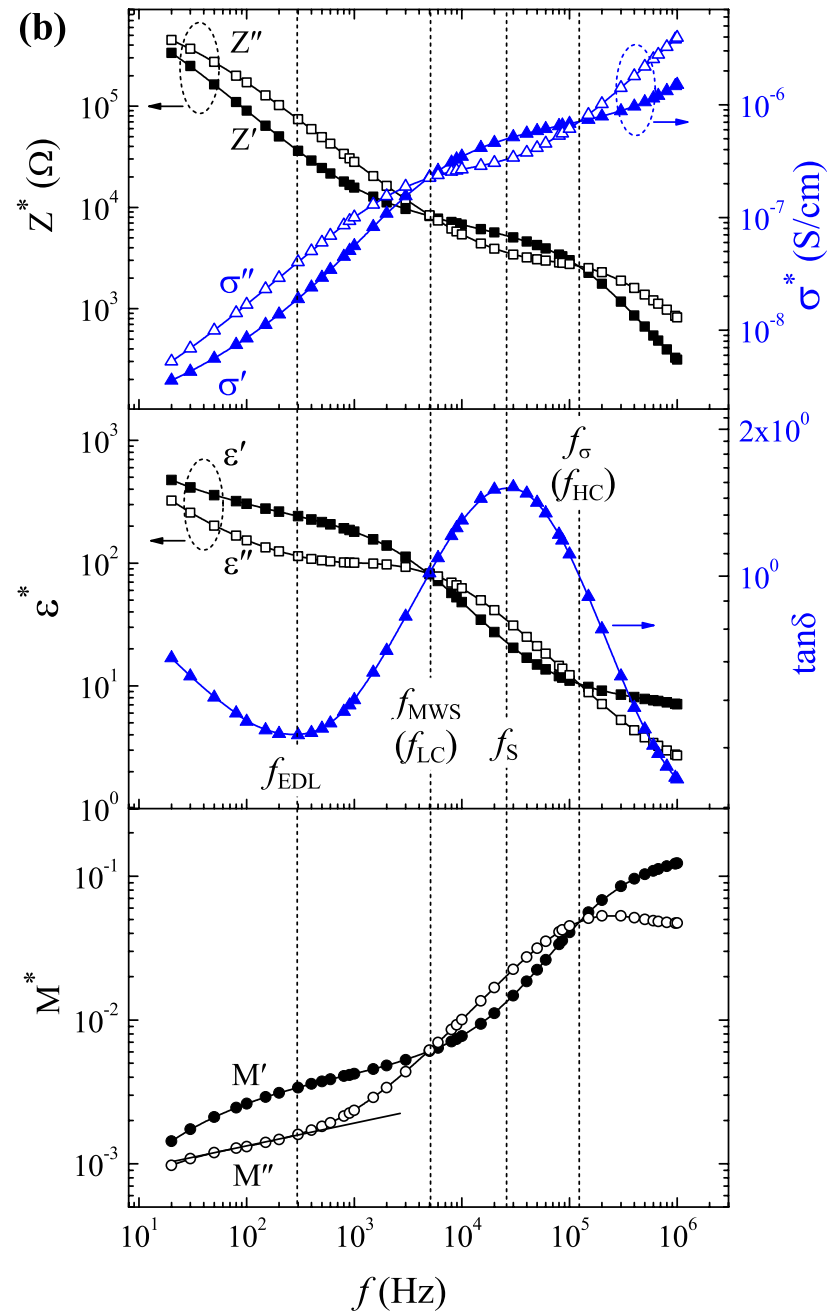

quency corresponding to different relaxation processes are marked with vertical dashed lines

also starts to deviate from linearity can be labeled to EDL relaxation process. The frequency corresponding to the peak in $\tan \delta$ spectra where $Z^{\prime \prime}$ and $\sigma^{\prime \prime}$ also exhibit minimum can be labeled to the ions coupled chain segmental relaxation process. The values of relaxation times for these processes i.e., $\tau_{E D L}, \tau_{M w S}, \tau_{s}$, and $\tau_{\sigma}$ are evaluated from the respective relaxation frequencies using the relation $\tau=1 / 2 \pi f$ and the observed values for these materials are listed in Table 2. The anomalous variation in these relaxation times with the increase of $\mathrm{TiO}_{2}$ concentration in these NSPE films is noted. These results confirm that the heterogeneous polymeric electrolyte films at ambient temperature, in general, might exhibit all four different relaxation processes when they are characterized by the DRS technique with six orders of frequency variation from $10^{1}$ to $10^{6} \mathrm{~Hz}$. 


\subsection{Dependence of $\sigma_{d c}$ on $\tau_{s}$ and $X_{c}$}

Figure 8 presents the variation of $\sigma_{\mathrm{d}^{\prime}} \tau_{\mathrm{s}^{\prime}}$ and $X_{\mathrm{c}}$ with $x$ wt $\%$ of $\mathrm{TiO}_{2}$ for these NSPE films at $27^{\circ} \mathrm{C}$, which are considered here to examine the dependence of $\sigma_{\mathrm{dc}}$ values on the $\tau_{\mathrm{s}}$ and $X_{c}$ values of these materials. It can be noted from this figure that the $X_{c(t)}$ of these NSPE films irregularly increase with the increase of $\mathrm{TiO}_{2}$ content, whereas $X_{\mathrm{c}(\mathrm{p})}$ decreases anomalously. The $\sigma_{\mathrm{dc}}$ values of these NSPEs up to $15 \mathrm{wt} \%$

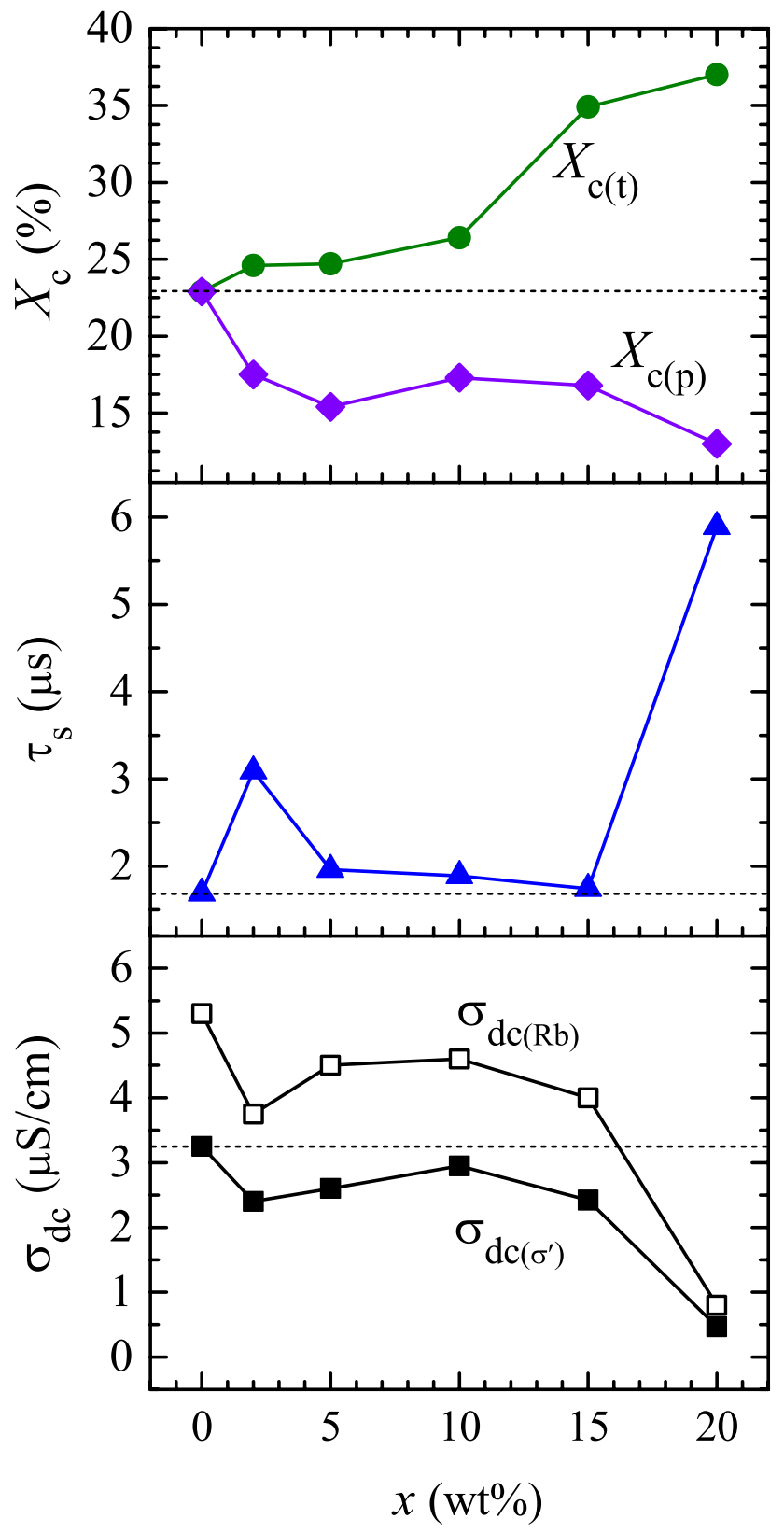

Fig. 8 Degree of crystallinity $X_{c}(\%)\left(X_{c(p)}\right.$ and $\left.X_{c(t)}\right)$, chain segmental relaxation time $\tau_{s}$ and dc ionic conductivity $\sigma_{\mathrm{dc}}\left(\sigma_{\mathrm{dc}\left(\sigma^{\prime}\right)}\right.$ and $\left.\sigma_{\mathrm{dc}(R b)}\right)$ versus $x$ (wt $\%)$ plots of (75PEO/25PVDF)/2 wt $\% \mathrm{LiClO}_{4}-x \mathrm{wt} \% \mathrm{TiO}_{2}$ films $(x=0,2,5,10,15$, and 20$)$, at $27^{\circ} \mathrm{C}$
$\mathrm{TiO}_{2}$ concentration are found slightly low as compared to NSPEO film without nanofiller but the conductivity is decreased by about one order of magnitude for $20 \mathrm{wt} \%$ $\mathrm{TiO}_{2}$ containing NSPE20 film. If only the NSPEO and NSPE20 films are considered, then from their results it can be firmly concluded that the increase of $X_{\mathrm{c}(\mathrm{t})}$ reduces the $\sigma_{\mathrm{dc}}$, but this fact is not found true for the NSPEs having $\mathrm{TiO}_{2}$ contents in the range $2-15 w t \%$. However, if the effect of $X_{c(p)}$ is taken into account, then the $\sigma_{\mathrm{dc}}$ values of all the NSPE films must be high as compared to NSPEO film without nanofiller because of their low $X_{c(p)}$ values. But this fact is also found invalid for all these electrolyte materials. Therefore, it cannot be concluded that only the degree of crystallinity (either of the host polymer matrix or the bulk composite electrolyte material) governs the ionic conductivity of such heterogeneous electrolyte materials.

The $\tau_{s}$ values are found a little higher for the NSPEs as compared to that of the NSPEO film, and therefore it can be concluded that the increase of $\tau_{\mathrm{s}}$ reduces the $\sigma_{\mathrm{dc}}$ values. For $20 \mathrm{wt} \% \mathrm{TiO}_{2}$ containing NSPE20 film, its $\tau_{s}$ is about half order high and the $\sigma_{\mathrm{dc}}$ is low by the same amount. For all these NSPE materials, an almost inverse relationship between the $\sigma_{\mathrm{dc}}$ and $\tau_{\mathrm{s}}$ values can be noted from Fig. 8. This fact establishes that the ion transportation is predominantly ruled by the relaxation time of ions coupled polymer chain segmental motion in these heterogeneous ion-dipole-nanofiller networks. This finding is in good agreement with the results on several other types of solid polymer electrolytes characterized by employing the DRS technique $[20,26,27,29,31-33,69,70]$. The comparison of $\sigma_{d c^{\prime}} \tau_{s^{\prime}}$ and $X_{c}$ values of these different wt $\% \mathrm{TiO}_{2}$ dispersed NSPE films also illustrates that their content of amorphous phase and the relative variation of ion coupled chain segmental dynamics compensate the effect of one another on the $\sigma_{\mathrm{dc}}$ values. For example, $15 \mathrm{wt} \% \mathrm{TiO}_{2}$ containing NSPE15 film has a large increase in $X_{c(t)}$ value and therefore, there must be a huge drop in its $\sigma_{\mathrm{dc}}$ value, but it is not there because the $\tau_{s}$ value of this film is relatively low. Similarly for NSPE20 film, both the $X_{c}$ and $\tau_{s}$ values are high and thus this film exhibits a relatively low value of $\sigma_{\mathrm{dc}}$ as expected in comparison to that of the lower $\mathrm{TiO}_{2}$ concentration NSPE films.

\subsection{Electrochemical performance}

The electrochemical parameters namely working voltage $\left(\mathrm{V}_{\mathrm{s}}\right)$, electrochemical stability window $(\mathrm{ESW})$, total ion transference number $\left(t_{\text {ion }}\right)$, and also reversibility performance of these NSPE films were explored from their $\mathrm{LSV}, \mathrm{CV}$, and CA traces recorded at $27^{\circ} \mathrm{C}$, and the same are depicted in Fig. 9.

The LSV traces of these NSPE films (Fig. 9a) clearly show that the current is almost zero with sweeping the voltage 

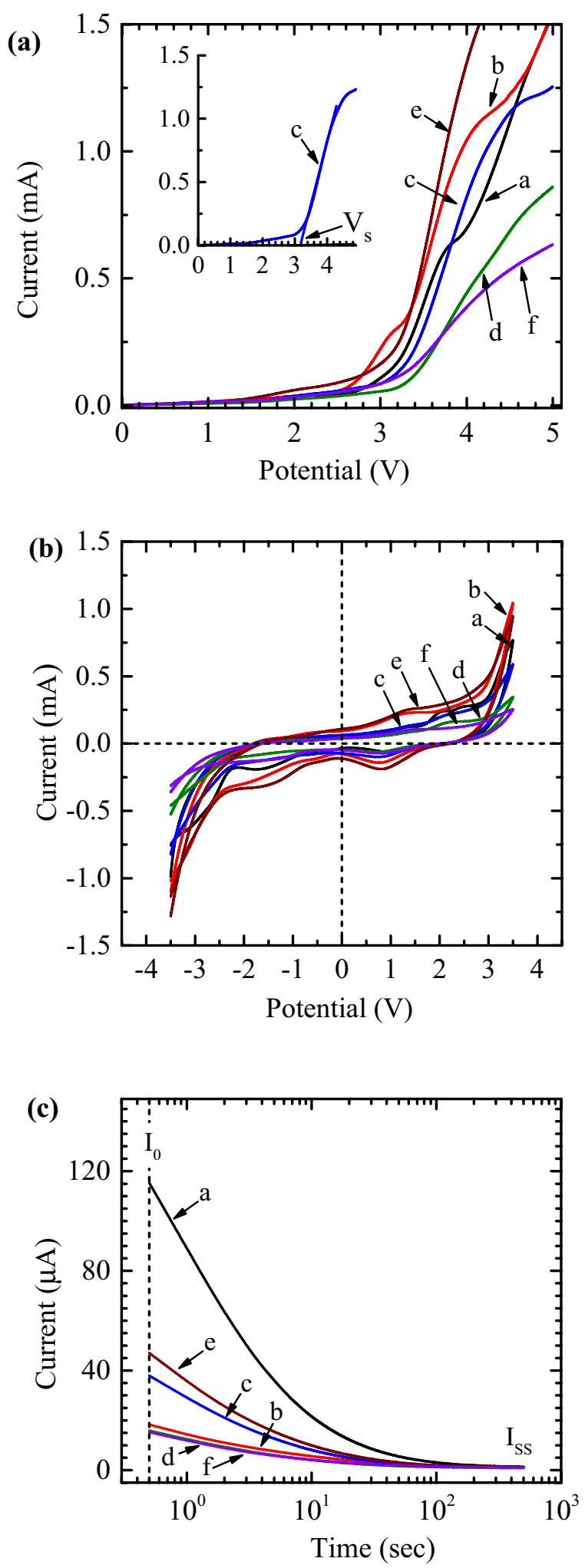

Fig. 9 a Linear sweep voltammograms (LSVs), b cyclic voltammograms (CVs), and c chronoamperograms (CAs) of (75PEO/25PVDF)/25 wt $\% \mathrm{LiClO}_{4}-x$ wt $\% \mathrm{TiO}_{2}$ films ( $x=0$ (a), 2 (b), 5 (c), 10 (d), $15(\mathrm{e})$, and $20(\mathrm{f}))$, at $27^{\circ} \mathrm{C}$

SN Applied Sciences from zero to about $3 \mathrm{~V}$ confirming the stability of the materials up to $3 \mathrm{~V}$, and after that, it increases rapidly indicating that some decomposition of the electrolytes have started on the blocking electrodes. The threshold voltage at which decomposition of the material starts is termed as stability voltage $\left(\mathrm{V}_{\mathrm{s}}\right)$, and for all the studied NSPE films its value is found $\geq 3 \mathrm{~V}$ which is a considerable value confirming them as potential candidates for the high voltage LIBs $[8,10,19$, $35,69,70]$. The CV traces of the NSPE films are presented in Fig. $9 \mathrm{~b}$ which reveals that all these electrolyte films exhibit excellent reversibility performance over the ESW range that is taken equal to $2 \mathrm{~V}_{s}$.

Figure $9 c$ depicts the CA traces from which it can be noted that the initial current $I_{0}$ is comparatively high for the NSPEO film and it varies anomalously with the increase of $\mathrm{TiO}_{2}$ concentration in these NSPE films. Further, current in these materials decreases rapidly with the increase of polarization time, and finally approach the steady state $I_{s s}$. The values of $I_{0}$ and $I_{\text {ss }}$ noted from CA traces were used for the determination of $t_{\text {ion }}$ values for these NSPE films using the relation given in recent publication [70], and the determined values are recorded in Table 2 . It can be read from this table that the $t_{\text {ion }}$ values of all these NSPE materials are close to unity confirming that the electrical conductivity is predominantly ionic, and therefore these materials can serve as an appropriate ionic conductor between the anode and cathode of a rechargeable solid-state lithiumion battery $[8,10]$.

\subsection{Effect of $\mathrm{TiO}_{2}$ on the ionic conductivity of various NSPE films: an overview}

Herein, the results of earlier investigations on the ionic conductivity of varying concentration $\mathrm{TiO}_{2}$ nanoparticles incorporated different polymer matrices based lithiumion conducting NSPE materials at ambient temperature are summarized for better understanding of the role of $\mathrm{TiO}_{2}$ nanofiller on the ion transportation. The increase in conductivity by about one and a half order of magnitude (i.e., from $7.1 \times 10^{-7}$ to $1.2 \times 10^{-5} \mathrm{~S} / \mathrm{cm}$ ) is reported for the (PEO-PVC)-LiPF 4 solid complexes with the loading of $10 \mathrm{wt} \% \mathrm{TiO}_{2}$ [18]. Similarly, it was noted that the ionic conductivity of PEO- $\mathrm{LiCF}_{3} \mathrm{SO}_{3}$ electrolyte had increased by one order of magnitude with $10 \mathrm{wt} \% \mathrm{TiO}_{2}$ addition (i.e., from $1.4 \times 10^{-6}$ to $4.9 \times 10^{-5} \mathrm{~S} / \mathrm{cm}$ ) [22]. Recently, in situ synthesized lithium-ion conducting poly(ethylene citrate) with embedded titania nanoparticles yielded a maximum increase of conductivity from $5.92 \times 10^{-6}$ to $1.74 \times 10^{-4} \mathrm{~S} / \mathrm{cm}$ for $20 \mathrm{wt} \%$ of $\mathrm{TiO}_{2}$ nanofiller [30]. For the plasticized PMMA- $\mathrm{LiClO}_{4}$ based NSPE films, a maximum ionic conductivity of $3 \times 10^{-4} \mathrm{~S} / \mathrm{cm}$ was observed for $1 \mathrm{wt} \%$ $\mathrm{TiO}_{2}$ nanoparticles with respect to $2.53 \times 10^{-6} \mathrm{~S} / \mathrm{cm}$ for the electrolyte film without nanofiller [53]. The PEO-LiTDI 
ion-dipole complexes also exhibited an increase in conductivity by one order of magnitude (i.e., from $2.05 \times 10^{-6}$ to $2.11 \times 10^{-5} \mathrm{~S} / \mathrm{cm}$ ) with the loading of $8 \mathrm{wt} \% \mathrm{TiO}_{2}$ [57]. One order of magnitude conductivity enhancement that is from $1.27 \times 10^{-6}$ to $1.20 \times 10^{-5} \mathrm{~S} / \mathrm{cm}$ was also reported for the PEO- $\mathrm{LiClO}_{4}$ electrolyte films when $3 \mathrm{wt} \% \mathrm{TiO}_{2}$ nanoparticles were dispersed [58]. A little increase in ionic conductivity from $3.1 \times 10^{-3}$ to $3.9 \times 10^{-3} \mathrm{~S} / \mathrm{cm}$ was observed for 3 wt\% in situ $\mathrm{TiO}_{2}$ inclusion for the PVDF/PMMA matrixbased gel polymer electrolytes (GPEs) [60]. The PVA-LiClO complex based NSPE films exhibited anomalous behaviour of ionic conductivity with the increase of $\mathrm{TiO}_{2}$ nanofiller but the highest value of conductivity was observed for $8 \mathrm{wt} \% \mathrm{TiO}_{2}$ loaded ion-dipole-nanoparticle complexes [61].

In the case of PEO-EMIHSO ${ }_{4}$ gel electrolytes, the enhancement of conductivity was observed by a factor of two which is from $0.85 \times 10^{-3}$ to $1.76 \times 10^{-3} \mathrm{~S} / \mathrm{cm}$ with the addition of $10 \mathrm{wt} \% \mathrm{TiO}_{2}$ nanofiller [62]. Further, the electrospun nanofibrous composite polymer electrolytes $\left(\mathrm{PEO} / \mathrm{LiClO}_{4} / \mathrm{PC} / \mathrm{EC} / \mathrm{TiO}_{2}\right)$ also exhibited the highest ionic conductivity $8.5 \times 10^{-5} \mathrm{~S} / \mathrm{cm}$ at $0.175 \mathrm{wt} \% \mathrm{TiO}_{2}$ nanofiller [51]. It was also reported that in comparison to the commercial $\mathrm{TiO}_{2}$ sub-micron as filler, the use of $\mathrm{TiO}_{2}$ nanorods is more effective in the enhancement of lithium-ion conductivity in the PVDF-HFP based composite polymer electrolytes [55]. The NSPEs based on $\mathrm{PMMA} / \mathrm{SAN} / \mathrm{EC} / \mathrm{PC} / \mathrm{LiCF}_{3} \mathrm{SO}_{3}$ complexes dispersed with $9 \mathrm{wt} \%$ anatase- $\mathrm{TiO}_{2}$ nanofiller exhibited high ionic conductivity $\left(1.05 \times 10^{-4} \mathrm{~S} / \mathrm{cm}\right)$ which is not because of the $\mathrm{TiO}_{2}$ filler alone but also due to the contribution of EC/ PC plasticizer [56]. The EC/DEC plasticized PVDF/PVC/ LiBOB complexes showed enhanced ionic conductivity up to $5.43 \times 10^{-4} \mathrm{~S} / \mathrm{cm}$ with $2.5 \mathrm{wt} \%$ of $\mathrm{TiO}_{2}$ nanofiller [76]. It is also noted that there is an enhancement of thermal and electrochemical properties of the PVDFHFP/PMMA/LiPF 6 electrolyte membrane with the addition of $\mathrm{TiO}_{2}$ nanoparticles and their ionic conductivity also enhances [77]. The plasticized nanocomposite solid polymer electrolyte membranes based on PEMA/PVAc/ $\mathrm{LiClO}_{4} / \mathrm{EC} / x \mathrm{wt} \% \mathrm{TiO}_{2}$ exhibited maximum ionic conductivity of $2.745 \times 10^{-3} \mathrm{~S} / \mathrm{cm}$ with $10 \mathrm{wt} \% \mathrm{TiO}_{2}$ loading [78]. Although these numerous studies on $\mathrm{TiO}_{2}$ nanoparticles incorporated NSPE materials claimed that this inorganic nanofiller increases the ionic conductivity of the electrolytes, there is a huge anomaly on the effective concentration of $\mathrm{TiO}_{2}$ nanofiller in regards to enhancement of ionic conductivity. Therefore, on the basis of above mentioned results, it is difficult to conclude firmly that a particular type of $\mathrm{TiO}_{2}$ and/or a fixed concentration is actually effective in tailoring the ionic conductivity of the NSPE materials. More recently, the effect of the shape of $\mathrm{TiO}_{2}$ nanofiller on the ionic conductivity of PEO- $\mathrm{LiClO}_{4}$ electrolytes has been explored [79]. This study concluded that the improvement of conductivity with $2 \mathrm{wt} \%$ $\mathrm{TiO}_{2}$ nanorods is one order of magnitude higher than that with $5 \mathrm{wt} \%$ elliptical $\mathrm{TiO}_{2}$ and it further explained the shape-property relationship in such NSPE materials.

In contrast to the above results, it was also explained that there is a little impact of the untreated surface $\mathrm{TiO}_{2}$ nanoparticles on the conductivity of polymeric electrolytes above the polymer melting temperature, but superacidic groups introduced on the nanoparticle surface can significantly increase the ionic conductivity [63]. Similar to these results, another study further revealed that the acidic surface-modified filler is more effective in the enhancement of ionic conductivity of the solid polymer electrolytes [64]. Furthermore, the characterization of $\mathrm{TiO}_{2}$-grafted nanohybrid polymer electrolytes exhibits superior electrochemical properties with an ionic conductivity of $1.1 \times 10^{-4} \mathrm{~S} / \mathrm{cm}$ at $30^{\circ} \mathrm{C}[80]$. Similarly, the results of $\mathrm{PVA} / \mathrm{PVDF} / \mathrm{LiCF}_{3} \mathrm{SO}_{3}$ electrolytes with $\mathrm{TiO}_{2}$ filler suggested that the addition of $\mathrm{TiO}_{2}$ filler slightly enhances the ionic conductivity [81]. Our recent investigation on fixed $\mathrm{TiO}_{2}$ concentration based plasticized nanocomposites solid polymer electrolytes evidenced that the high concentration of PC plasticizer along with $10 \mathrm{wt} \% \mathrm{TiO}_{2}$ nanofiller slightly enhances the ionic conductivity i.e., by a factor of about two only [69].

But some studies have firmly demonstrated that there is a lowering of ionic conductivity of the solid polymer electrolytes upon the addition of inert inorganic oxide nanofillers $[20,82,83]$. The results of atomistic molecular dynamics simulations performed on $\mathrm{PEO}-\mathrm{LiBF}_{4}$ complexes with $\mathrm{TiO}_{2}$ and $\mathrm{Al}_{2} \mathrm{O}_{3}$ nanoparticles proved that the segmental dynamics becomes retarded with the addition of inorganic nanofiller near the surface of nanoparticles and also disrupt the polymer conformation resulting a huge decrease of ions mobility and therefore the ionic conductivity of these composite electrolyte $[65,66,84]$. The recent results on coin cell employed NSPE film of PVDF-HFP/LiBOB/TiO (72:18:10 wt\%) also confirmed that the ionic conductivity slightly decreased $\left(1.27 \times 10^{-6} \mathrm{~S} / \mathrm{cm}\right)$ as compared to that of the PVDF-HFP/LiBOB electrolyte without nanofiller $\left(2.02 \times 10^{-6} \mathrm{~S} / \mathrm{cm}\right)$ [85]. The results of the present study on the ionic conductivity of (PEO/PVDF)/ $/ \mathrm{LiClO}_{4}-x \mathrm{wt} \%$ $\mathrm{TiO}_{2}$ films are also found in good agreement with those reported without nanofiller because the decrease in $\sigma_{\mathrm{dc}}$ with the addition of untreated surface $\mathrm{TiO}_{2}$ nanoparticles is insignificant up to $15 \mathrm{wt} \%$ loading. Further, the correlation of $\sigma_{\mathrm{dc}}$ with the chain segmental dynamics which mainly governs the mobility of ions reasonably supported several facts as explained in regards to variation in ionic conductivity with the addition of $\mathrm{TiO}_{2}$ nanoparticles and other inorganic nanofillers as summarized for all the above mentioned studies [20, 63-66, 80-84]. 


\section{Conclusions}

Various NSPE films of (75PEO/25PVDF)/25 wt $\% \mathrm{LiClO}_{4}-x$ $\mathrm{wt} \% \mathrm{TiO}_{2}$ compositions were prepared by casting from solution. The effect of $\mathrm{TiO}_{2}$ nanofiller concentration on the morphological, structural, dielectric polarization and relaxation, ionic conduction, and electrochemical properties of these NSPE films was investigated. The XRD results of these electrolytes confirm the presence of a small amount of characteristic PEO crystallites and the $\beta$-phase crystals of PVDF, and also unveil significant alteration in these polymers crystals with the addition of $\mathrm{TiO}_{2}$ nanoparticles. The degree of crystallinity of the blend polymer matrix significantly decreased and that of the bulk composite materials increased in the presence of $\mathrm{TiO}_{2}$ nanoparticles. The homogeneous dispersion of the $\mathrm{TiO}_{2}$ nanoparticles is evidenced from the increase in intensities of the characteristic $\mathrm{TiO}_{2}$ peaks with the increase in its amount in these nanocomposite electrolytes. Further, the morphology of these NSPE films drastically changes with the initial addition of $\mathrm{TiO}_{2}$ nanoparticles and with the further increase of its concentration.

The dielectric spectroscopic results confirm that these heterogeneous dielectric materials have a dominant contribution of electrode polarization at lower frequencies, interfacial polarization at intermediate frequencies, and molecular and ionic polarization at high frequencies in the frequency range of $20 \mathrm{~Hz}-1 \mathrm{MHz}$ at $27^{\circ} \mathrm{C}$. The relaxation processes corresponding to these polarizations have been demonstrated by the 'master curve representation' of the complex dielectric and electric spectra, simultaneously. The real part of ac electrical conductivity of these NSPE films obeys Jonscher power law in the high frequency region with fractional exponent values $\simeq 0.50$ to 0.73 confirming that the transport of ions occurs through hopping and the chain segmental dynamics facilitate this mechanism.

The $\sigma_{\mathrm{dc}}$ values thus obtained are found maximum for the NSPEO film without nanofiller, whereas the dispersion of 2 to $15 \mathrm{wt} \% \mathrm{TiO}_{2}$ has lead to a small decrease in the ionic conductivity. Further, about one order of magnitude drop in the ionic conductivity value has been observed for the $20 \mathrm{wt} \% \mathrm{TiO}_{2}$ containing NSPE20 film. The comparative results on conductivity and relaxation time unveil the adverse effect of $\mathrm{TiO}_{2}$ nanoparticles addition on the ion conduction in these PEO/PVDF blend matrix-based NSPE materials. The electrochemical performance of all these NSPE materials is found appreciable regarding their suitability in the development of all-solid-state ion-conducting devices.

Acknowledgements One of the authors (RJS) is indebted to the Department of Science and Technology (DST), New Delhi, for providing experimental facilities through the DST-FIST program project No. SR/FST/PSI-134/2008, and also to the Government of Rajasthan, Jaipur, through Rashtriya Uchchatar Shiksha Abhiyan (RUSA) grant No. F30(16)SPD/RUSA/2016/218. The author (PD) appreciatively acknowledges the award of Post Doctoral Fellowship (File No. 09/098 (0133)18 EMR-I) by the Council of Scientific and Industrial Research (CSIR), New Delhi.

\section{Compliance with ethical standards}

Conflict of interest The authors declare that they have no conflict of interest.

\section{References}

1. Zhang H, Armand M, Rojo T (2019) Review-innovative polymeric materials for better rechargeable batteries: strategies from CIC Energigune. J Electrochem Soc 166:A679-A686

2. Yue L, Ma J, Zhang J, Zhao J, Dong S, Liu Z, Cui G, Chen L (2016) All solid-state polymer electrolytes for high-performance lithium ion batteries. Energy Storage Mater 5:139-164

3. Zhang Q, Liu K, Ding F, Liu X (2017) Recent advances in solid polymer electrolytes for lithium batteries. Nano Res 10:4139-4174

4. Kalhoff J, Eshetu GG, Bresser D, Passerini S (2015) Safer electrolytes for lithium-ion batteries: state of the art and perspectives. Chemsuschem 8:2154-2175

5. Xue Z, He D, Xie X (2015) Poly(ethylene oxide)-based electrolytes for lithium-ion batteries. J Mater Chem A 3:19218-19253

6. Ngai KS, Ramesh S, Ramesh K, Juan JC (2016) A review of polymer electrolytes: fundamental, approaches and applications. lonics 22:1259-1279

7. Gracia I, Armand M, Shanmukaraj D (2019) Li metal polymer batteries. In: Murugan R, Weppner W (eds) Solid electrolytes for advanced applications. Springer, Cham

8. Arya A, Sharma AL (2017) Insights into the use of polyethylene oxide in energy storage/conversion devices: a critical review. J Phys D: Appl Phys 50:443002

9. He T, Jing $M$, Yang $H$, Chen $H$, Hua $S$, Ju B, Zhou $Q$, Tu F, Shen X, Qin S (2019) Effects of gelation behavior of PPC-based electrolyte on electrochemical performance of solid state lithium battery. SN Appl Sci 1:205

10. Winie T, Arof AK, Thomas S (2020) Polymer electrolyte: characterization techniques and energy applications. Wiley-VCH Verlag GmbH \& Co KGaA, Weinheim

11. Aldalur I, Matinez-lbañez M, Krztoń-Maziopa A, Piszcz M, Armand M, Zhang H (2019) Flowable polymer electrolytes for lithium metal batteries. J Power Sources 423:218-226

12. Kisliuk A, Bocharova V, Popov I, Gainaru C, Sokolov AP (2019) Fundamental parameters governing ion conductivity in polymer electrolytes. Electrochim Acta 299:191-196

13. Monaca AL, Giorgio FD, Focarete ML, Fabiani D, Zaccaria $M$, Arbizzani C (2017) Polyvinylidene difluoride-polyethyleneoxide blends for electrospun separators in Li-ion batteries. J Electrochem Soc 164:A6431-A6439

14. Patla SK, Ray R, Asokan K, Karmakar S (2018) Investigation of ionic conduction in PEO-PVDF based blend polymer electrolytes. J Appl Phys 123:125102

15. Elashmawi IS, Elsayed NH, Altalhi FA (2014) The changes of spectroscopic, thermal and electrical properties of PVDF/PEO containing lithium nanoparticles. J Alloys Compd 617:877-883

16. Deng F, Wang X, He D, Hu J, Gong C, Ye YS, Xie X, Xue Z (2015) Microporous polymer electrolyte based on PVDF/PEO star polymer blends for lithium ion batteries. J Membr Sci 491:82-89 
17. Wang X, Hao X, Hengjing Z, Xia X, Tu J (2020) 3D ultraviolet polymerized electrolyte based on PEO modified PVDF-HFP electrospun membrane for high-performance lithium-sulfur batteries. Electrochim Acta 329:135108

18. Arya A, Sadiq M, Sharma AL (2018) Effect of variation of different nanofillers on structural, electrical, dielectric, and transport properties of blend polymer nanocomposites. Ionics 24:2295-2319

19. Arya A, Sharma AL (2019) Temperature and salt-dependent dielectric properties of blend solid polymer electrolyte complexed with LiBOB. Macromol Res 27:334-345

20. Choudhary S, Sengwa RJ (2017) Effects of different inorganic nanoparticles on the structural, dielectric and ion transportation properties of polymers blend based nanocomposite solid polymer electrolytes. Electrochim Acta 247:924-941

21. Dhatarwal P, Choudhary S, Sengwa RJ (2018) Electrochemical performance of $\mathrm{Li}^{+}$-ion conducting solid polymer electrolytes based on PEO-PMMA blend matrix incorporated with various inorganic nanoparticles for the lithium ion batteries. Compos Commun 10:11-17

22. Vignarooban K, Dissanayake MAKL, Albinsson I, Mellander BE (2014) Effect of $\mathrm{TiO}_{2}$ nano-filler and $\mathrm{EC}$ plasticizer on electrical and thermal properties of poly(ethylene oxide) (PEO) based solid polymer electrolytes. Solid State lonics 266:25-28

23. Wang YJ, Kim D (2007) Crystallinity, morphology, mechanical properties and conductivity study of in situ formed PVdF/ $\mathrm{LiClO}_{4} / \mathrm{TiO}_{2}$ nanocomposite polymer electrolytes. Electrochim Acta 52:3181-3189

24. Mejia A, Devaraj S, Guzmán J, del Amo JML, García N, Rojo T, Armand M, Tiemblo P (2016) Scalable plasticized polymer electrolytes reinforced with surface-modified sepiolite fillers A feasibility study in lithium metal polymer batteries. J Power Sources 306:772-778

25. Duan H, Yin YX, Zeng XX, Li JY, Shi JL, Shi Y, Wen R, Guo YG, Wan LJ (2018) In-situ plasticized polymer electrolyte with doublenetwork for flexible solid-state lithium-metal batteries. Energy Storage Mater 10:85-91

26. Dhatarwal P, Sengwa RJ (2017) Effects of PEG plasticizer concentrations and film preparation methods on the structural, dielectric and electrical properties of PEO-PMMA blend based plasticized solid polymer electrolyte films. Indian J Pure Appl Phys 55:7-18

27. Das S, Ghosh A (2015) Effect of plasticizers on ionic conductivity and dielectric relaxation of $\mathrm{PEO}-\mathrm{LiClO}_{4}$ polymer electrolyte. Electrochim Acta 171:59-65

28. Liu Y, Xu B, Zhang W, Li L, Lin Y, Nan C (2019) Composition modulation and structure design of inorganic-in-polymer composite solid electrolytes for advanced lithium batteries. Small. https://doi.org/10.1002/smll.201902813

29. Sengwa RJ, Dhatarwal P, Choudhary S (2014) Role of preparation methods on the structural and dielectric properties of plasticized polymer blend electrolytes: Correlation between ionic conductivity and dielectric parameters. Electrochim Acta 142:359-370

30. Pignanelli $F$, Romero $M$, Castiglioni J, Faccio R, Mombrú AW (2019) Novel synergistic in situ synthesis of lithium-ion poly(ethylene citrate)- $\mathrm{TiO}_{2}$ nanocomposites as promising fluorine-free solid polymer electrolytes for lithium batteries. J Phys Chem Solids 135:109082

31. Sengwa RJ, Dhatarwal P, Choudhary S (2015) Effects of plasticizer and nanofiller on the dielectric dispersion and relaxation behaviour of polymer blend based solid polymer electrolytes. Curr Appl Phys 15:135-143

32. Dhatarwal P, Sengwa RJ (2018) Influence of solid polymer electrolyte preparation methods on the performance of
(PEO-PMMA)- $\mathrm{LiBF}_{4}$ films for lithium-ion battery applications. Polym Bull 75:5645-5666

33. Choudhary S, Sengwa RJ (2013) Effects of preparation methods on structure, ionic conductivity and dielectric relaxation of solid polymeric electrolytes. Mater Chem Phys 142:172-181

34. Prasanth R, Shubha N, Hng HH, Srinivasan M (2014) Effect of poly(ethylene oxide) on ionic conductivity and electrochemical properties of poly(vinylidenefluoride) based polymer gel electrolytes prepared by electrospinning for lithium ion batteries. $J$ Power Sources 245:283-291

35. Dhatarwal P, Sengwa RJ (2019) Synergistic effects of salt concentration and polymer blend composition on the crystal phases, dielectric relaxation, and ion conduction in PVDF/PEO/LiCF $\mathrm{SO}_{3}$ solid polymer electrolytes. Ionics. https://doi.org/10.1007/s1158 1-019-03337-2

36. Jacob MME, Prabaharan SRS, Radhakrishna S (1997) Effect of PEO addition on the electrolytic and thermal properties of PVDF-LiClO 4 polymer electrolytes. Solid State Ion 104:267-276

37. Yang K, Chi Q, Wang X, Jiang Y, Li F, Xue B (2019) The role of halloy site on crystallinity, ion conductivity, thermal and mechanical properties of poly(ethylene-oxide)/halloysite nanocomposites. J Polym Res 26:138

38. Hasan N, Pulst M, Samiullah MH, Kressler J (2019) Comparison of $\mathrm{Li}^{+}$-ion conductivity in linear and crosslinked poly(ethylene oxide). J Polym Sci: Part B 57:21-28

39. Dhatarwal P, Sengwa RJ, Choudhary S (2019) Effectively improved ionic conductivity of montmorillonite clay nanoplatelets incorporated nanocomposite solid polymer electrolytes for lithium ion-conducting devices. SN Appl Sci 1:112

40. Utpalla P, Sharma SK, Sudarshan K, Sahu M, Pujari PK (2019) Investigation of the free volume characteristics of PEO based solid state polymer electrolyte by means of positron annihilation spectroscopy. Solid State Ion 339:114990

41. Singh MD, Dalvi A, Phase DM, Kumar Y (2020) $\mathrm{Li}_{13} \mathrm{Al}_{03} \mathrm{Ti}_{17}\left(\mathrm{PO}_{4}\right)_{3}$ reinforced hybrid polymer composites: assessment of enhanced $\mathrm{Li}^{+}$ion transport and potential for solid-state supercapacitor applications. J Mater Sci 55:3951-3963

42. Dhatarwal P, Sengwa RJ (2019) Polymers compositional ratio dependent morphology, crystallinity, dielectric dispersion, structural dynamics, and electrical conductivity of PVDF/PEO blend films. Macromol Res 27:1009-1023

43. Arya A, Sharma AL (2018) Effect of salt concentration on dielectric properties of $\mathrm{Li}$-ion conducting blend polymer electrolytes. J Mater Sci 29:17903-17920

44. Martins P, Lopes AC, Lanceros-Mendez S (2014) Electroactive phases of poly(vinylidene fluoride): determination, processing and applications. Prog Polym Sci 39:683-706

45. Lee YY, Liu YL (2017) Crosslinked electrospun poly(vinylidene difluoride) fiber mat as a matrix of gel polymer electrolyte for fastcharging lithium-ion battery. Electrochim Acta 258:1329-1335

46. Wang F, Li L, Yang X, You J, Xu Y, Wang H, Ma Y, Gao G (2018) Influence of additives in a PVDF-based solid polymer electrolyte on conductivity and Li-ion battery performance. Sustain Energy Fuels 2:492-498

47. Barbosa JC, Dias JP, Lanceros-Méndez S, Costa CM (2018) Recent advances in poly(vinylidene fluoride) and its copolymers for lithium-ion battery separators. Membranes 8:45

48. Lee L, Park S-J, Kim S (2013) Effect of nano-sized barium titanate addition on PEO/PVDF blend-based composite polymer electrolytes. Solid State Ion 234:19-24

49. Han H, Liu W, Zhang J, Zhao X-Z (2005) A hybrid poly(ethylene oxide)/ poly(vinylidene fluoride) $/ \mathrm{TiO}_{2}$ nanoparticle solid-state redox electrolyte for dye-sensitized nanocrystalline solar cells. Adv Funct Mater 15:1940-1944

50. Xi J, Qiu X, Li J, Tang X, Zhu W, Chen L (2006) PVDF-PEO blends based microporous polymer electrolyte: Effect of PEO on 
pore configurations and ionic conductivity. J Power Sources 157:501-506

51. Banitaba SN, Semnani D, Rezaei B, Ensafi AA (2019) Evaluating the electrochemical properties of PEO-based nanofibrous electrolytes incorporated with $\mathrm{TiO}_{2}$ nanofiller applicable in lithium-ion batteries. Polym Adv Tech 30:1234-1242

52. Chen $\mathrm{P}$, Liang $X$, Wang J, Zhang D, Yang S, Wu W, Zhang W, Fan X, Zhang D (2017) PEO/PVDF-based gel polymer electrolyte by incorporating nano- $\mathrm{TiO}_{2}$ for electrochromic glass. J Sol-Gel Technol 81:850-858

53. Pal $\mathrm{P}$, Ghosh $\mathrm{A}$ (2018) Influence of $\mathrm{TiO}_{2}$ nano-particles on charge

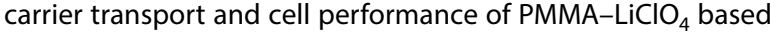
nano-composite electrolytes. Electrochim Acta 260:157-167

54. Arya A, Saykar NG, Sharma AL (2019) Impact of shape (nanofiller vs. nanorod) of $\mathrm{TiO} 2$ nanoparticle on free-standing solid polymeric separator for energy storage/conversion devices. J Appl Polym Sci 136:47361

55. Kumar PS, Sakunthala A, Govindan K, Reddy MV, Prabu M (2016) Single crystalline $\mathrm{TiO}_{2}$ nanorods as effective fillers for lithium ion conducting PVdF-HFP based composite polymer electrolytes. RSC Adv 6:91711-91719

56. Ganesan SV, Mothilal KK, Selvasekarapandian S, Ganesan TK (2018) The effect of titanium dioxide nano-filler on the conductivity, morphology and thermal stability of poly(methyl methacrylate)poly(styrene-co-acrylonitrile) based composite solid polymer electrolytes. J Mater Sci 29:8089-8099

57. Polu AR, Rhee H-W (2016) Effect of $\mathrm{TiO}_{2}$ nanoparticles on structural, thermal, mechanical and ionic conductivity studies of

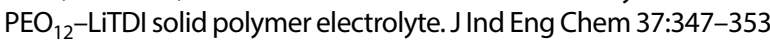

58. Zha J-W, Huang N, He KQ, Dang Z-M, Shi C-Y, Li RK (2017) Electrospun poly(ethylene oxide) nanofibrous composites with enhanced ionic conductivity as flexible solid polymer electrolytes. High Volt 2:25-31

59. Liu Y, Lee JY, Hong L (2003) Morphology, crystallinity, and electrochemical properties of in situ formed poly(ethylene oxide)/ $\mathrm{TiO}_{2}$ nanocomposite polymer electrolytes. J Appl Polym Sci 89:2815-2822

60. Zhou L, Wu N, Cao Q, Jing B, Wang X, Wang Q, Kuang H (2013) A novel electrospun PVDF/PMMA gel polymer electrolyte with in situ $\mathrm{TiO}_{2}$ for $\mathrm{Li}$-ion batteries. Solid State lon 249-250:93-97

61. Lim C-S, Teoh KH, Liew C-W, Ramesh S (2014) Capacitive behavior studies on electrical double layer capacitor using poly (vinyl alcohol)-lithium perchlorate based polymer electrolyte incorporated with $\mathrm{TiO}_{2}$. Mater Chem Phys 143:661-667

62. Ketabi S, Lian K (2015) The effects of $\mathrm{SiO}_{2}$ and $\mathrm{TiO}_{2}$ nanofillers on structural and electrochemical properties of poly(ethylene oxide)$\mathrm{EMIHSO}_{4}$ electrolytes. Electrochim Acta 154:404-412

63. Syzdek J, Borkowska R, Perzyna K, Tarascon JM, Wieczorek W (2007) Novel composite polymeric electrolytes with surface-modified inorganic fillers. J Power Sources 173:712-720

64. Ganapatibhotla LVNR, Maranas JK (2014) Interplay of surface chemistry and ion content in nanoparticle-filled solid polymer electrolytes. Macromolecules 47:3625-3634

65. Hanson B, Pryamitsyn V, Ganesan V (2013) Mechanisms underlying ionic mobilities in nanocomposite polymer electrolytes. ACS Macro Lett 2:1001-1005

66. Mogurampelly S, Ganesan V (2015) Effect of nanoparticles on ion transport in polymer electrolytes. Macromolecules 48:2773-2786

67. Ganesan S, Balamurugan S, Karthika P, Marimuthu M (2019) Influence of synthesized pyridine and tetra ethylene glycol derivatives in poly (vinylidene fluoride)/poly (ethylene oxide) with Ti coated back contact dye-sensitized solar cells. Sol Energy 189:667-684

68. Dhatarwal P, Sengwa RJ (2019) Impact of PVDF/PEO blend composition on the $\beta$-phase crystallization and dielectric properties of silica nanoparticles incorporated polymer nanocomposites. J Polym Res 26:196
69. Dhatarwal P, Sengwa RJ (2020) Dielectric relaxation, Li-ion transport, electrochemical, and structural behaviour of PEO/PVDF/ $\mathrm{LiClO}_{4} / \mathrm{TiO}_{2} / \mathrm{PC}$-based plasticized nanocomposite solid polymer electrolyte films. Compos Commun 17:182-191

70. Sengwa RJ, Dhatarwal P (2020) Predominantly chain segmental relaxation dependent ionic conductivity of multiphase semicrystalline PVDF/PEO/LiClO 4 solid polymer electrolytes. Electrochim Acta 338:135890

71. Sengwa RJ, Dhatarwal P, Choudhary S (2018) Study of time-ageing effect on the ionic conduction and structural dynamics in solid polymer electrolytes by dielectric relaxation spectroscopy. Solid State lon 324:247-259

72. Xu P, Fu W, Cui Z, Ding Y (2018) Enhancement of polar phase and conductivity relaxation in PIL-modified GO/PVDF composites. Appl Phys Lett 112:063904

73. Sengwa RJ, Choudhary S, Dhatarwal P (2019) Nonlinear optical and dielectric properties of $\mathrm{TiO}_{2}$ nanoparticles incorporated PEO/ PVP blend matrix based multifunctional polymer nanocomposites. J Mater Sci 30:12275-12294

74. Sengwa RJ, Choudhary S (2014) Dielectric properties and fluctuating relaxation processes of poly (methyl methacrylate) based polymeric nanocomposite electrolytes. J Phys Chem Solids 75:765-774

75. Choudhary S, Dhatarwal P, Sengwa RJ (2019) Probing the dielectric relaxation processes and their correlation with ions transportation in the complexes of plasticized nanocomposite solid polymer electrolyte. Indian J Phys 93:1545-1558

76. Aravindam $\mathrm{V}$, Vickraman $\mathrm{P}$ (2007) Effects of $\mathrm{TiO}_{2}$ and $\mathrm{ZrO}_{2}$ nanofillers in LiBOB based PVdF/PVC composite polymer electrolytes (CPE). J Phys D 40:6754

77. Song DY, Xu C, Chen YF, He JR, Zhao Y, Li PJ, Lin W, Fu F (2015) Enhanced thermal and electrochemical properties of PVDF-HFP/ PMMA polymer electrolyte by $\mathrm{TiO}_{2}$ nanoparticles. Solid State Ion 282:31-36

78. Premila R, Subbu C, Rajendran S, Selva kumar K, (2018) Experimental investigation of nano filler $\mathrm{TiO}_{2}$ doped composite polymerelectrolytes for lithium ion batteries. Appl Surf Sci 449:426-434

79. Vasudevan S, Fullerton-Shirey SK (2019) Effect of nanoparticle shape on the electrical and thermal properties of solid polymer electrolytes. J Phys Chem C 123:10720-10726

80. Ma C, Zhang J, Xu M, Xia Q, Liu J, Zhao S, Chen L, Pan A, Ivey DG, Wei W (2016) Cross-linked branching nanohybrid polymer electrolyte with monodispersed $\mathrm{TiO}_{2}$ nanoparticles for high performance lithium-ion batteries. J Power Sources 317:103-111

81. Hema M, Tamilselvi P (2016) Lithium ion conducting PVA:PVdF polymer electrolytes doped with nano $\mathrm{SiO}_{2}$ and $\mathrm{TiO}_{2}$ filler. J Phys Chem Solids 96-97:42-48

82. Johansson P, Ratner MA, Shriver DF (2001) The Influence of inert oxide fillers on poly(ethylene oxide) and amorphous poly(ethylene oxide) based polymer electrolytes ${ }^{\dagger}$. J Phys Chem B 105:9016-9021

83. Walls HJ, Zhou J, Yerian JA, Fedkiw PS, Khan SA, Stowe MK, Baker GL (2000) Fumed silica-based composite polymer electrolytes: synthesis, rheology, and electrochemistry. J Power Sources 89:156-162

84. Mogurampelly S, Ganesan V (2016) Influence of nanoparticle surface chemistry on ion transport in polymer nanocomposite electrolytes. Solid State lon 286:57-65

85. Sabrina Q, Sohib A, Lestariningsih T, Ratri CR (2019) The effect of $\left(\mathrm{TiO}_{2}\right.$ and $\left.\mathrm{SiO}_{2}\right)$ nano-filler on solid polymer electrolyte based LiBOB. J Phys Conf Series 1191:012028

Publisher's Note Springer Nature remains neutral with regard to jurisdictional claims in published maps and institutional affiliations. 